\title{
A review of recent research on the use of zeotropic mixtures in power generation systems
}

\section{Modi, Anish; Haglind, Fredrik}

\section{Published in:}

Energy Conversion and Management

Link to article, DOI:

10.1016/j.enconman.2017.02.032

Publication date:

2017

Document Version

Peer reviewed version

Link back to DTU Orbit

Citation (APA):

Modi, A., \& Haglind, F. (2017). A review of recent research on the use of zeotropic mixtures in power generation systems. Energy Conversion and Management, 138, 603-626. https://doi.org/10.1016/j.enconman.2017.02.032

\section{General rights}

Copyright and moral rights for the publications made accessible in the public portal are retained by the authors and/or other copyright owners and it is a condition of accessing publications that users recognise and abide by the legal requirements associated with these rights.

- Users may download and print one copy of any publication from the public portal for the purpose of private study or research.

- You may not further distribute the material or use it for any profit-making activity or commercial gain

- You may freely distribute the URL identifying the publication in the public portal

If you believe that this document breaches copyright please contact us providing details, and we will remove access to the work immediately and investigate your claim 


\title{
A review of recent research on the use of zeotropic mixtures in power generation systems
}

\author{
Anish Modi ${ }^{\mathrm{a}, *}$, Fredrik Haglind ${ }^{\mathrm{b}}$ \\ ${ }^{a}$ Department of Energy Science and Engineering, Indian Institute of Technology Bombay, Powai, Mumbai \\ 400076, Maharashtra, India \\ ${ }^{b}$ Department of Mechanical Engineering, Technical University of Denmark, Nils Koppels Allé, Building \\ 403, DK-2800 Kgs. Lyngby, Denmark
}

\begin{abstract}
The use of zeotropic fluid mixtures in refrigeration cycles and heat pumps has been widely studied in the last three decades or so. However it is only in the past few years that the use of zeotropic mixtures in power generation applications has been analysed in a large number of studies, mostly with low grade heat as the energy source. This paper presents a review of the recent research on power cycles with zeotropic mixtures as the working fluid. The available literature primarily discusses the thermodynamic performance of the mixture power cycles through energy and exergy analyses but there are some studies which also consider the economic aspects through the investigation of capital investment costs or through a thermoeconomic analysis. The reviewed literature in this paper is divided based on the various applications such as solar energy based power systems, geothermal heat based power systems, waste heat recovery power systems, or generic studies. The fluid mixtures used in the various studies are listed along with the key operation parameters and the scale of the power plant. In order to limit the scope of the review, only the studies with system level analysis of various power cycles are considered. An overview of the key trends and general conclusions from the various studies and some possible directions for future research are also presented.
\end{abstract}

Keywords: Zeotropic mixture, Temperature glide, Power generation, Organic Rankine cycle, Ammonia-water mixture, Kalina cycle 


\section{Introduction}

Fluid mixtures have been widely studied for their use in refrigeration systems and heat pumps in the past few decades [1]. These include mixtures of natural as well as artificial refrigerants and could either be azeotropic or zeotropic. For an azeotropic mixture, the 5 compositions of the liquid and the vapour phases are the same for a certain combination of temperature and pressure [1]. The state where this happens is called the azeotropic point. This point is highlighted in Fig. 1 for a binary azeotropic mixture with the azeotropic point boiling temperature lower than the boiling temperatures of both the pure fluid constituents of the mixture.

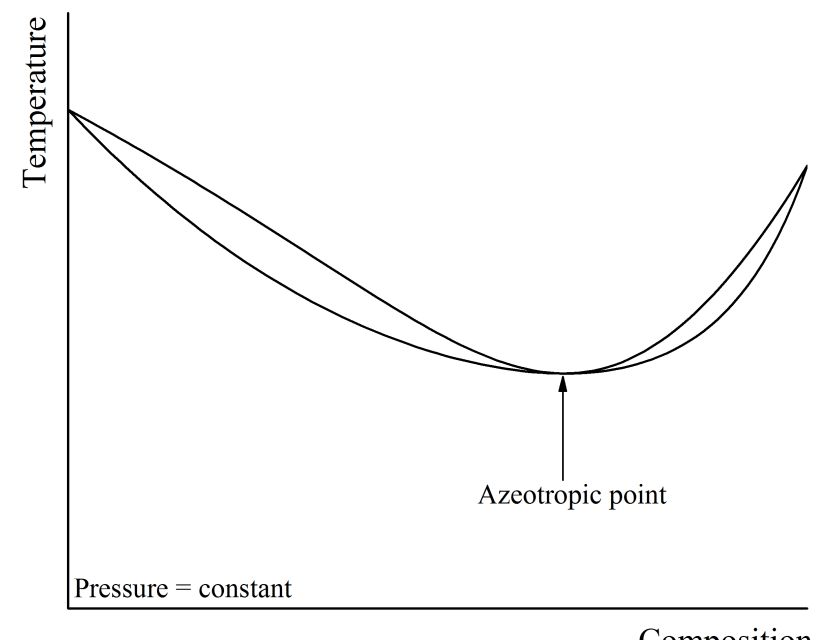

Composition

Figure 1: Schematic temperature-composition diagram for a binary azeotropic mixture at a constant pressure.

For a zeotropic mixture, on the other hand, the compositions of the liquid and the vapour phases are always different in the two-phase region. These mixtures have sometimes also been referred to as non-azeotropic mixtures. The temperature-composition diagram for a binary zeotropic mixture is shown in Fig. 2. In the figure, for any bulk fluid composition $x$ at a state $k$ in the two-phase region, the points ' $\mathrm{A}$ ' and ' $\mathrm{B}$ ' represent respectively the dew

\footnotetext{
${ }^{*}$ Corresponding author. Tel. +91222576 9340 .

Email address: anishmodi@iitb.ac.in (Anish Modi)
} 


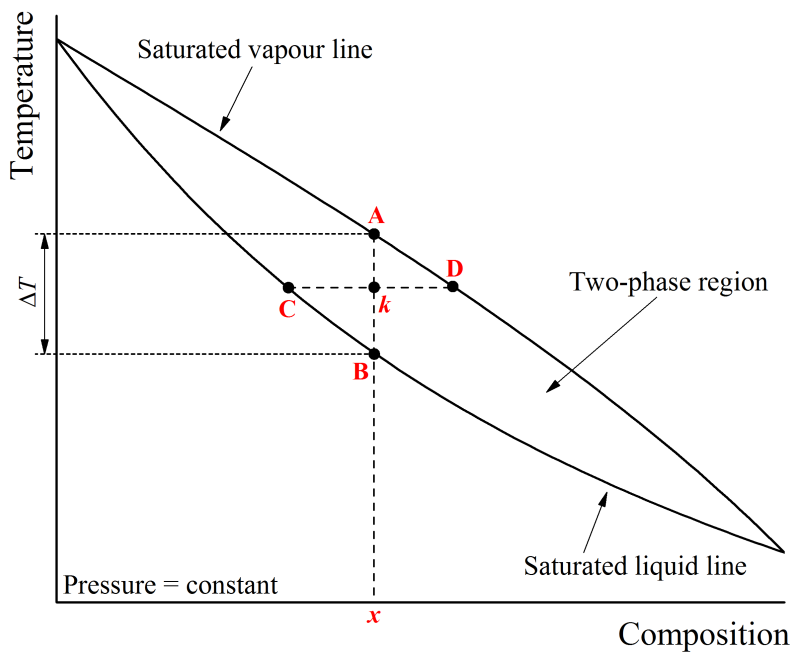

Figure 2: Schematic temperature-composition diagram for a binary zeotropic mixture at a constant pressure.

point and the bubble point temperatures for the mixture. The points ' $\mathrm{C}$ ' and ' $\mathrm{D}$ ' represent the liquid and the vapour saturation points for the equilibrium liquid and vapour phase compositions at that state, respectively. The temperature difference $\Delta T$ on the vertical axis of the figure represents the temperature glide for the mixture, i.e. the difference between the bubble and dew points for a particular mixture composition at a specified evaporation pressure. The composition here could either be the mole or the mass fraction with respect to one of the components. This temperature glide occurs during evaporation because of the evaporation of the more volatile component of the mixture first, thereby resulting in different compositions in the liquid and the vapour phases, and thus the continuously changing evaporation temperature at the same pressure until the entire mixture is evaporated. The same phenomenon is observed during condensation because of the condensation of the less volatile component of the mixture first.

In recent years, the use of fluid mixtures in power cycles has attracted increased interest because of the possibility to reduce the irreversibility during a two-phase heat transfer process, enabling to increase the average temperature of heat supply and/or decrease the average temperature of heat rejection, thereby resulting in better thermodynamic performance in terms of improved cycle efficiency. This reduction comes through the matching 
of the temperature profiles of the fluid mixture with those of the heat source and sink during evaporation and condensation, respectively, because of the occurrence of non-isothermal phase change.

This paper presents a review of the recent literature on the use of zeotropic mixture in power generation applications. The key conclusions drawn from the state-of-the-art along with guidelines for future research are also presented. The reviewed literature is divided based on the various applications such as solar energy based power systems, geothermal heat based power systems, waste/exhaust heat recovery (WHR) power systems, or generic

\section{Organic Rankine cycle power systems}

The use of ORC power systems has been investigated for many applications, operation conditions, and capacities [5-8]. Working fluid selection has been one of the key areas of research $[9,10]$ and a list of the various investigated fluids along with their alternative

of the mixture ORCs based on the respective applications. A list of the recommended fluid mixtures from the studies comparing various mixtures for different applications is presented in Section 4. 


\subsection{Solar energy based ORC power systems} to heat source temperatures between around $80{ }^{\circ} \mathrm{C}$ and $150{ }^{\circ} \mathrm{C}$ and for plant capacities in the $\mathrm{kW}$ range. All the studies have evaluated the solar energy based ORC power systems through energy and exergy analyses while a few also conducting sensitivity analysis. In these studies, mostly hydrocarbon mixtures have been evaluated for the assumed operation conditions and generation capacities. Table 1 shows an overview of these studies with their details presented in the following text. In the studies where comparisons were made between the use of pure fluids and fluid mixtures, Table 1 presents the details corresponding to the mixture analysis. 
Table 1: Studies with solar energy based ORC power systems. $T_{\mathrm{hs}}$ is the heat source temperature and $T_{\mathrm{cs}}$ is the cooling medium temperature.

A '-' instead of the value indicates unavailable data.

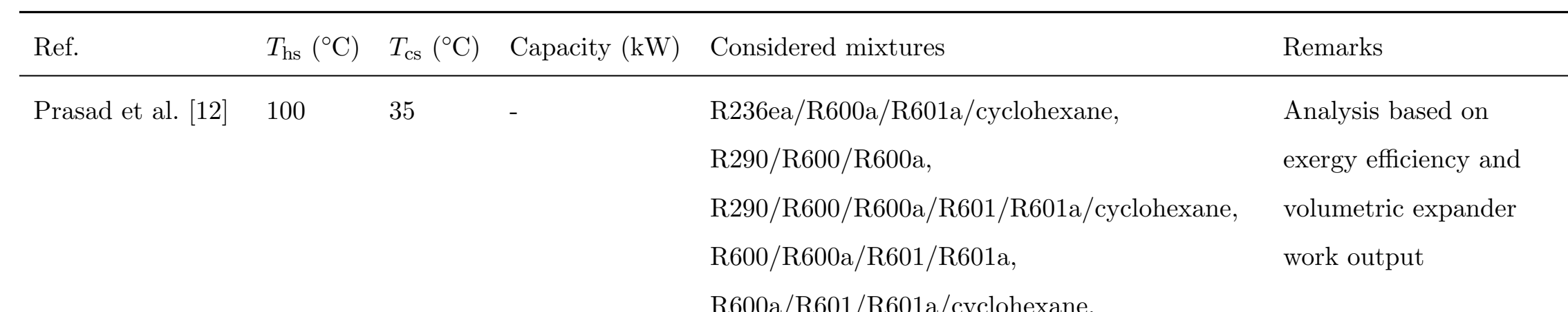

R600a/R601/R601a/cyclohexane,

R600a/R601a/cyclobutane/cyclohexane,

R601a/cyclopentane/cyclohexane

o Baldasso

et al. [13]

Bao et al. [14]

$95-155^{\dagger}$

Wang and

Zhao [15]
150

20

100

Various binary mixture combinations using

R1234yf, R1234ze, R600, R600a, R601, R601a, cyclopentane, hexane, cyclohexane, and

isohexane

R245fa/R601a
$\mathrm{R} 152 \mathrm{a} / \mathrm{R} 245 \mathrm{fa}$

$85^{\dagger} \quad 25^{\ddagger} \quad 21.3-25.3 \quad \mathrm{R} 152 \mathrm{a} / \mathrm{R} 245 \mathrm{fa}$

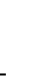




\begin{tabular}{|c|c|c|c|c|c|}
\hline Garg et al. [16] & $127-300$ & $35^{\ddagger}$ & - & $\mathrm{CO}_{2} / \mathrm{R} 290$ and $\mathrm{CO}_{2} / \mathrm{R} 601 \mathrm{a}$ & $\begin{array}{l}\text { Energy and exergy } \\
\text { analyses }\end{array}$ \\
\hline Garg et al. [17] & $107-152$ & $35^{\ddagger}$ & 100 & $\mathrm{R} 245 \mathrm{fa} / \mathrm{R} 601 \mathrm{a}$ & $\begin{array}{l}\text { Energy and exergy } \\
\text { analyses }\end{array}$ \\
\hline Mavrou et al. [18] & $80-95$ & $30^{\ddagger}$ & 1 & $\begin{array}{l}\text { R600/R601, R600a/R601, R600a/R601a, } \\
\text { R601/hexane, R601a/hexane, } \\
\text { R601a/isohexane, } \\
\text { 1,1,1,3,3,3-hexafluoropropane/1-fluoromethoxy- } \\
\text { 2,2,2-trifluoromethylethane, } \\
\text { neopentane/1,1,1-trifluoro-2- } \\
\text { trifluoromethylbutane, } \\
\text { neopentane/1,1,1-trifluoropentane, } \\
\text { 1,1,1-trifluoro-2-trifluoromethylpropane/2,2- } \\
\text { difluorohexane }\end{array}$ & $\begin{array}{l}\text { Energy, exergy, and } \\
\text { sensitivity analyses }\end{array}$ \\
\hline Mavrou et al. [19] & $80-95$ & - & 1 & $\begin{array}{l}\text { R600a/R601, 1,1,1-trifluoropropane/2- } \\
\text { fluoromethoxypropane, } \\
\text { 1,1,1-trifluoropropane/1- } \\
\text { fluoromethoxypropane, } \\
\text { neopentane/1,1,1-trifluoro-2- } \\
\text { trifluoromethylbutane, } \\
\text { neopentane/2-fluoromethoxy-2-methylpropane }\end{array}$ & $\begin{array}{l}\text { Energy, exergy, and } \\
\text { sensitivity analyses }\end{array}$ \\
\hline Mavrou et al. [20] & $80-95$ & $30^{\ddagger}$ & 1 & $\begin{array}{l}\text { Various binary mixture combinations using } \\
\text { hydrocarbons and hydrofluorocarbons }\end{array}$ & $\begin{array}{l}\text { Energy, exergy, and } \\
\text { sensitivity analyses }\end{array}$ \\
\hline
\end{tabular}




\section{${ }^{\dagger}$ Expander inlet temperature.}

$\ddagger$ Working fluid condenser outlet temperature. 
Prasad et al. [12] analysed the performance of an ORC unit for power generation using solar thermal energy. The investigated layout consisted of an internal recuperator. The objective of the analysis was to maximize the exergy efficiency or the volumetric expander work output (i.e. the ratio of the expander power output to the volume flow rate of the working fluid at the expander outlet). The cycle performance was compared when using pure fluids and mixtures as the cycle working fluid. The main contribution of the paper was an approach to design suitable mixtures that can work with off-the-shelf expanders already available in the market, instead of having to come up with novel expander designs to suit the optimal working fluid. Baldasso et al. [13] presented a comparison between pure and mixed working fluids for an ORC unit operating with a parabolic trough solar field. The results indicated that the mixture of cyclopentane/cyclohexane performed better than its pure components in terms of the overall plant efficiency. Bao et al. [14] proposed a novel auto-cascade power cycle using mixtures as shown in Fig. 3. The results indicated that the optimal working fluid composition was different for the cycle configurations with and without the regenerator, and the solar collector I outlet temperature affected the cycle thermal efficiency most significantly. 


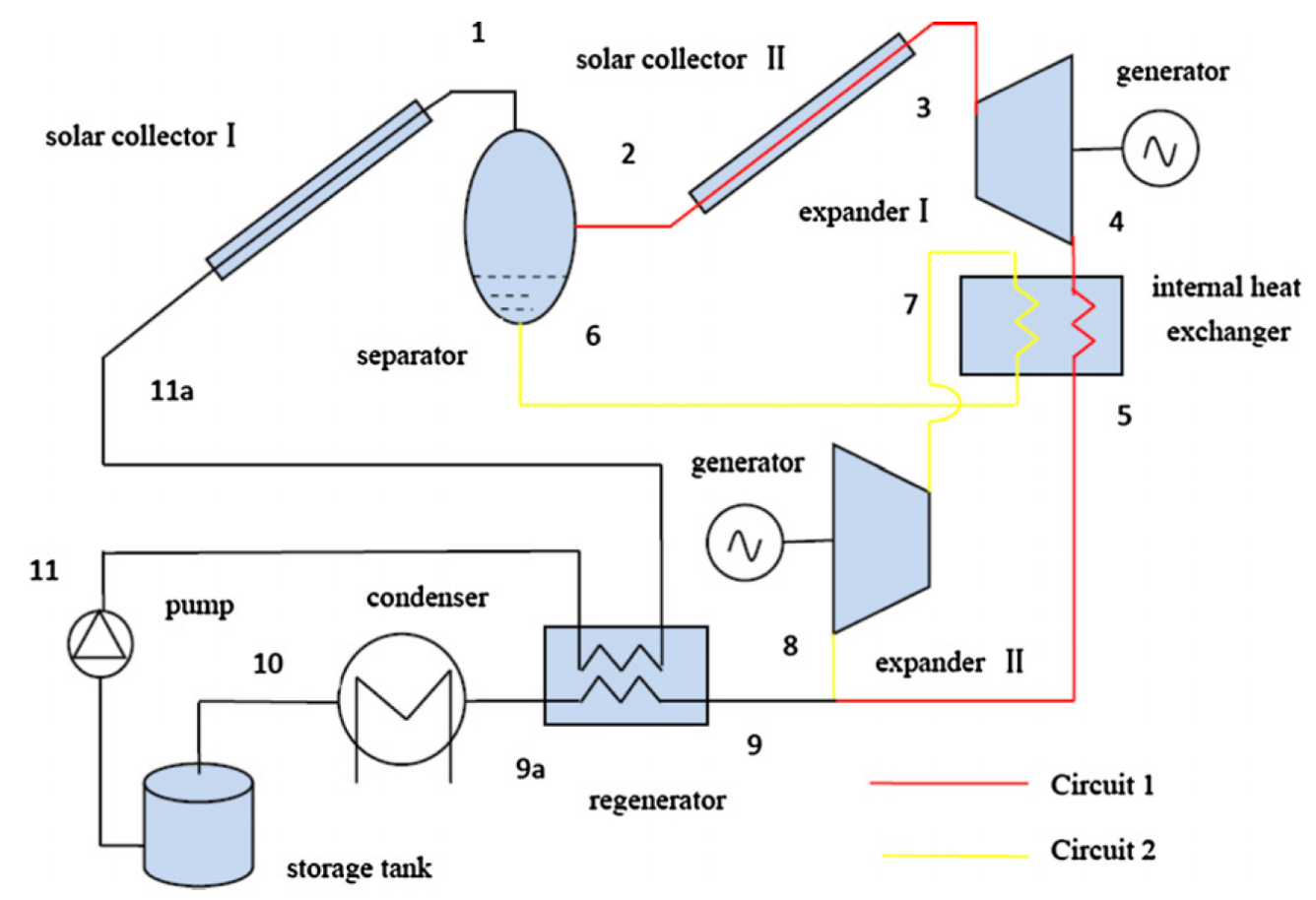

Figure 3: Auto-cascade low temperature solar power cycle [14].

Wang et al. $[15,21]$ presented the numerical and experimental analyses of low-temperature solar power cycles. A comparison was made between using different compositions of the working fluid mixture. Pure R245fa was found to result in the highest cycle efficiency among the compared alternatives. However, this came at the cost of requiring larger expander dimensions. Garg et al. $[16,17]$ evaluated the use of various mixture blends for use in solar ORC plants through energy and exergy analyses. For the blends with $\mathrm{CO}_{2}$, the $\mathrm{CO}_{2} / \mathrm{R} 290$ mixture performed similarly as pure propane, but with higher operating pressures. For the R245fa/R601a mixture, a 0.3/0.7 mole fraction mixture was found to be optimal because of reduced respective disadvantages of the pure components, i.e. the flammability and the high global warming potential. Mavrou et al. [18-20] analysed various conventional and novel working fluid mixtures for solar energy based ORC power systems. Energy and exergy analyses were performed along with a detailed sensitivity analysis and comparisons of the cycle performance were made on the basis of net power output and cycle thermal efficiency. 


\subsection{Geothermal heat based ORC power systems} heat source temperatures between around $70{ }^{\circ} \mathrm{C}$ and $150{ }^{\circ} \mathrm{C}$ and for plant capacities ranging between few $\mathrm{kW}$ to few MW. A couple of studies also considered higher heat source temperatures up to around $200{ }^{\circ} \mathrm{C}$. The mixtures of hydrocarbons have been evaluated the most through thermodynamic (energy and exergy), thermoeconomic, and experimental analyses. Multi-objective optimizations including both thermodynamic and economic parameters have also been performed by some researchers. Table 2 shows an overview of these studies with their details presented in the following text. In the studies where comparisons were made between the use of pure fluids and fluid mixtures, Table 2 presents the details corresponding to the mixture analysis. 
Table 2: Studies with geothermal heat based ORC power systems. $T_{\mathrm{hs}}$ is the heat source temperature and $T_{\mathrm{cs}}$ is the cooling medium temperature. A '-' instead of the value indicates unavailable data.

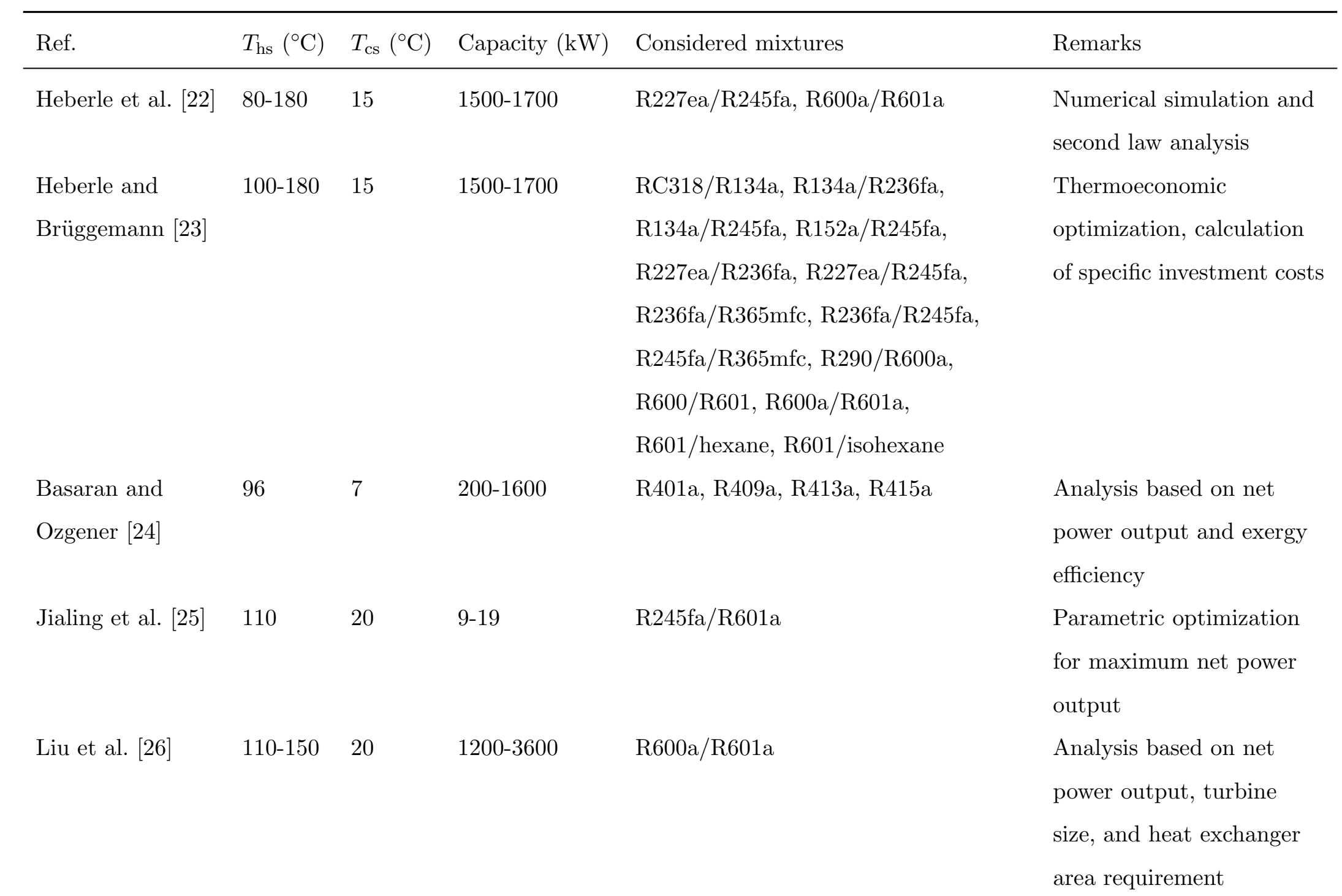


๗

$\begin{array}{llll}\begin{array}{l}\text { Oyewunmi and } \\ \text { Markides [31] }\end{array} & & 20 & 160-215 \\ \text { Sadeghi et al. [32] } & 100 & 25^{\ddagger} & 640-975 \\ & & & \\ \text { Habka and } & 80-120 & 15 & 7-35 \\ \text { Ajib [33] } & & & \\ & & & \\ \text { Lu et al. [34] } & 140 & 20 & 24-39 \\ \text { Baik et al. [35] } & 100 & 20 & 340\end{array}$

Yue et al. [27]

90-140

R600a/R601a
Li et al. [28]
$70-120$
$0.5^{\diamond}$

Yin et al. [29]

140-190 10

Kang et al. [30]

110

20

8-30

$-$

$\mathrm{CO}_{2} / \mathrm{SF}_{6}$
R1234yf/R600a, R1234yf/R601a, R1234ze/R600a, R1234ze/R601a, R134a/R600a, R134a/R601a,

R227ea/R600a, R227ea/R601a,

R245fa/R600a, R245fa/R601a

R227ea/R245fa, R601/hexane

R22m, R402a, R404a, R407a, R410a,

R422a, R438a, R402b, R403b, R422d

R22m, R402a, R404a, R407a, R410a,

R422a, R437a, R438a, R402b, R403b,

$\mathrm{R} 422 \mathrm{~d}$

R245fa/R600a and R600/R601a

R125/R134a, R125/R227ea,

R125/R236ea, R125/R245fa
Temperature profile

matching in the

evaporator and condenser

Experimental study with scroll expander

Analysis based on cycle efficiency

Parametric optimization

for highest net power

output

Multi-objective cost-power optimization

Thermodynamic analysis and multi-objective

optimization

Analysis with and without

cogeneration

Parametric study

Transcritical ORC power system 


\begin{tabular}{|c|c|c|c|c|c|}
\hline $\begin{array}{l}\text { Radulovic and } \\
\text { Castaneda [36] }\end{array}$ & $87-207$ & 15 & - & RC318/R143a, R124/R143a & $\begin{array}{l}\text { Parametric optimization } \\
\text { of a transcritical ORC } \\
\text { power system }\end{array}$ \\
\hline $\begin{array}{l}\text { Preißinger } \\
\text { et al. [37] }\end{array}$ & $100-190$ & 15 & $2800-3650^{\diamond}$ & R227ea/R245fa & $\begin{array}{l}\text { Economic comparison } \\
\text { between subcritical and } \\
\text { transcritical ORC power } \\
\text { systems }\end{array}$ \\
\hline
\end{tabular}

$\diamond$ Expander capacity.

$\ddagger$ Working fluid condenser outlet temperature. 
Heberle et al. [22, 23] presented detailed numerical simulations and thermoeconomic optimization of an ORC unit for low enthalpy geothermal sources. An ORC unit with a recuperator was optimized and analysed. From the thermodynamic perspective, the results indicated in a higher second law efficiency with fluid mixtures than with pure working fluids because of the non-isothermal phase change [22]. This was mainly because of a better matching of the hot and cold temperature profiles in the heat exchangers. In particular, the irreversibility in the condensers decreased significantly. The results also indicated that the operating configurations where the temperature profiles in the condenser matched better were the more efficient ones. From the thermoeconomic perspective, the specific investment costs for the cycle using mixtures was found to be higher than for the cycle using pure working fluids [23]. This was mainly because of lower values of two-phase heat transfer coefficients for the mixtures than those for the pure fluids resulting in larger heat exchanger area requirements for the mixture cycle. However, because of the higher power generation and higher annual electricity production as a result of lower irreversibility, the electricity generation costs were found to be lower when using mixtures by between $4 \%$ and $10 \%$ as compared with using pure fluids. In short, the higher investment costs were compensated by the higher amount of electricity generation from the plants using mixtures, thus resulting in better economic performance in terms of electricity generation costs when using mixtures as compared with using pure working fluids. 


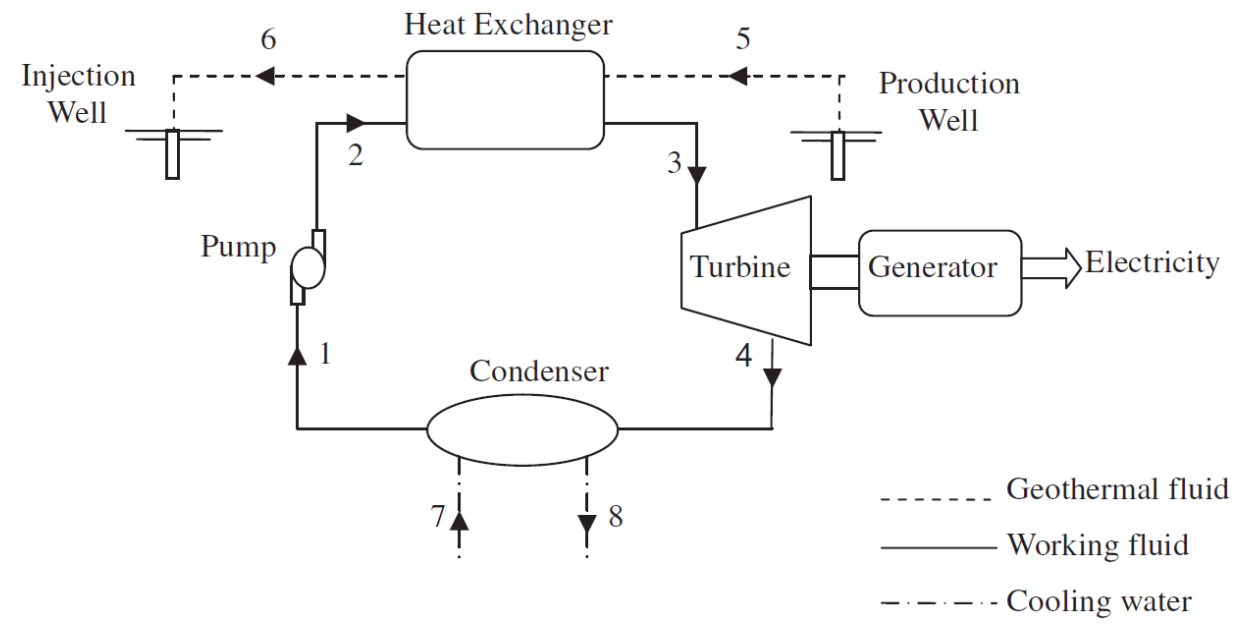

Figure 4: Basic geothermal heat based ORC power system [24].

Basaran and Ozgener [24] analysed a basic ORC unit for geothermal power production and compared the use of several pure and mixed working fluids. The cycle is shown in Fig. 4. The results indicated that for the analysed operating conditions, the considered mixtures were only better than two of the eight pure working fluids in terms of the net power output and the exergy efficiency of the plant. Jialing et al. [25] presented a parametric optimization of a geothermal ORC power system using a R245fa/R601a mixture as the working fluid. The optimal composition and operating conditions for the maximum net power output were determined. Liu et al. [26] presented the parametric optimization and performance analysis of a geothermal ORC power system with R600a/R601a as the working fluid. The performance of the plant was evaluated in terms of net power output, turbine size, and heat exchanger area requirements. Optimal fluid compositions were determined for the different performance indicators. The same mixture was also analysed by Yue et al. [27] with respect to the hot and cold side temperature profile matching in the evaporator and the condenser. Optimal temperature differences in the different heat exchangers were determined. Li et al. [28] experimentally compared the performances of ORCs using pure R245fa with that of ORCs using R245fa/R601a mixture with a scroll expander. The use of fluid mixture resulted in slightly higher cycle thermal efficiency (by about 0.07 percentage point). Yin et al. [29] evaluated the use of $\mathrm{CO}_{2} / \mathrm{SF}_{6}$ mixture in a geothermal Rankine cycle power system with a 
recuperator. Compositions resulting in the highest cycle efficiency were determined.

Kang et al. [30] performed the parametric optimization and performance analysis of a geothermal ORC power system with zeotropic mixtures. The results suggested the presence of an optimal mixture composition resulting in the maximum net power output for every mixture. This optimal composition was found to be the one that resulted in the maximum temperature glide in the evaporator. The presence of an optimal evaporating temperature was also noticed. Oyewunmi and Markides [31] presented a thermoeconomic and heat transfer optimization of fluid mixtures for geothermal ORC power systems. A multi-objective cost-power optimization was performed and optimal fluid mixtures and their compositions were identified for the highest thermodynamic efficiency and the lowest capital investment costs. The cycles with pure fluids were found to be generally cheaper than those with fluid mixtures. Sadeghi et al. [32] presented a thermodynamic analysis and multi-objective optimization of various ORC configurations (with one or two evaporators) using zeotropic mixtures as working fluid. The decision variables included the evaporation pressure, the minimum pinch point temperature difference, and the degree of superheat. The results indicated a $24 \%$ to $28 \%$ increase in power generation using mixtures than with pure working fluids. Habka and Ajib [33] evaluated the performance of geothermal ORC power systems with mixtures for plant configurations with and without cogeneration. The results showed that the power generation and heat source utilization may be improved by using mixtures. Lu et al. [34] presented the results from a parametric analysis of two ORC configurations, with one and two recuperators, respectively. The analysis was performed by varying the condenser bubble temperature and the condenser cooling water temperature rise and mass flow rate.

Some studies have also investigated the use of transcritical ORCs for geothermal power plants where the working fluid mixture is evaporated in a supercritical state, i.e. at pressures greater than the critical pressure, while the condensation takes place in the subcritical state. Baik et al. [35] presented an analysis of a mixture transcritical cycle in order to estimate the potential increase in the power output from the plant. The numerical analysis included 
working fluids on the basis of the heat exchanger area requirement. The rates of exergy destruction in the various cycle components were also calculated. The mixture transcritical cycle resulted in about $11 \%$ higher power generation than the pure fluid subcritical cycle under same simulation conditions, primarily because of lower irreversibility in the heating process. Radulovic and Castaneda [36] presented a parametric optimization of six zeotropic mixture compositions in a transcritical ORC. The results indicated that the cycles with the evaluated mixtures showed higher thermal efficiencies by up to $15 \%$ than those with the respective pure components at the same operational conditions. Preißinger et al. [37] presented a comparison between using pure and mixed working fluids in subcritical and transcritical cycle configurations from an economic perspective. The results suggested that for a heat source temperature equal to $130{ }^{\circ} \mathrm{C}$, the subcritical configurations generated higher gross power than the transcritical configurations. However, using transcritical ORCs with pure fluids or subcritical ORCs with fluid mixtures result in either similar or lower payback periods than the subcritical ORCs with pure fluids even with relatively higher specific investment costs. The analysis in this work assumed same total capital investment costs for the subcritical, the transcritical, and the fluid mixture power cycle systems.

\subsection{Waste/Exhaust heat recovery ORC power systems}

The studies on the use of ORC power systems for WHR applications have been conducted for a wide range of heat source temperatures (between around $50{ }^{\circ} \mathrm{C}$ and $560{ }^{\circ} \mathrm{C}$ ) and plant capacities (between around $0.5 \mathrm{~kW}$ and $74 \mathrm{MW}$ ). The various mixtures have been evaluated based on first law, second law, and economic analyses. The studies have provided general guidelines on the selection of optimal fluids and mixture compositions for various operating conditions and types of heat sources. Table 3 shows an overview of these studies with their details presented in the following text. The applications include heat recovery from diesel engine exhaust, flue gas from gas turbines or coal-fired power plants, industrial waste heat, and other similar sources. In the studies where comparisons were made between the use of pure fluids and fluid mixtures, Table 3 presents the details corresponding to the mixture analysis. 
Table 3: Studies with ORC units used for WHR applications. $T_{\mathrm{hs}}$ is the heat source temperature and $T_{\mathrm{cs}}$ is the cooling medium temperature. A '-' instead of the value indicates unavailable data.

\begin{tabular}{llllll}
\hline Ref. & $T_{\mathrm{hs}}\left({ }^{\circ} \mathrm{C}\right)$ & $T_{\mathrm{cs}}\left({ }^{\circ} \mathrm{C}\right)$ & Capacity $(\mathrm{kW})$ & Considered mixtures & Remarks \\
\hline Hærvig et al. $[38]$ & $50-280$ & 15 & - & R170/R290, R290/R600, R290/R601 & Guidelines for selection \\
& & & & of optimal working & fluids
\end{tabular}

$\begin{array}{llll}\text { Oyewunmi } & 330 \quad 20 & \text { R00-30000 } & \text { R600/decane, } \\ \text { et al. }[39] & & \text { perfluorobutane/perfluorodecane }\end{array}$

\section{Analysis based on net}

Li et al. $[40] \quad 150 \quad 20 \quad 20-100$

$\ddot{0}$

Mondejar and $\quad 77-177 \quad 17 \quad 3-45.8$
Thern [41]

$\begin{array}{lllll}\text { Xiao et al. [42] } & 150 & 20 & 2-90 & \\ & & & \text { R245fa/R600a, R245fa/R601, } \\ & & & \text { R245fa/R601a, R600a/R601a } \\ \text { Wu et al. }[43] & 120-170 & 15 & - & \text { R13I1/R601a, R245fa/R601a }\end{array}$

Li and Dai [44] $250 \quad 17 \quad$ 180-310 R123/R245fa, R600a/R601a

Binary mixture combinations of various pure fluids from the REFPROP database

Binary mixture combinations of various pure fluids from the REFPROP database

\section{based on net power}

output

Multi-objective

optimization

Matching of pinch

point temperature

differences

Thermoeconomic

analysis 
Kolahi et al. [45] $\quad 425.7 \quad 20 \quad 40-80$

Le et al. [46]

150

20

1040-1620

Feng et al. [47]

150

20

$1.4-2$



Heberle and
Brüggemann [50]

Guo et al. [51]

150

15

325

130

20

1450
R245fa/R601

R227ea/R245fa Analysis with exergy efficiency and LCOE

$\mathrm{MDM} / \mathrm{MM}$

R236ea/hexane, R236ea/cyclohexane,

R236ea/isohexane, R245fa/hexane,

R245fa/cyclohexane, R245fa/isohexane

R245fa/R601

R600a/R601a

R600a/R601
Thermodynamic and

economic analyses

Thermodynamic and

economic optimizations

Analysis based on

exergy efficiency and

LCOE

Analysis based on

second law efficiency

with and without

cogeneration

Thermoeconomic

analysis

Analysis based on first

law efficiency, heat

exchanger area,

volumetric flow rate,

and other parameters

CNG engine

Diesel engine

$\begin{array}{lllll}\text { Song et al. [52] } & 485-560 & 35^{\ddagger} & 2.6-62.8 & \text { R416a } \\ \text { Wang et al. [53] } & 170-545 & 30^{\ddagger} & 0.6-22.9 & \text { R416a }\end{array}$


Zhang et al. [5

$50-5$

35

Jung et al. [55]

158.7

15.3

Yang et al. [56]

$170-545$

30

Yang et al. [57]

200-550

30

$0.5-35$

Zhou et al. [58]

$\stackrel{N}{\sim} \quad$ Shu et al. [59]

Song and $\mathrm{Gu}[60]$

300

25

$80-90$

Braimakis

150-300

et al. [61]

Lee et al. [62] $\begin{array}{lll}87.7 & -160^{*} \quad 74100\end{array}$
R245fa/R601a (0.3/0.7 mole fraction)

R365mfc/R245fa (0.515/0.485 mole

fraction)

R401a, R402b, R407b, R407d, R409a,

R409b, R411b, R415b

R152a/R245fa

RC318/R1234yf, RC318/R245fa,

R1234yf/R600

R11/benzene, R11/cyclopentane,

R11/cyclohexane, R123/benzene,

R123/cyclopentane, R123/cyclohexane

R11/cyclohexane, R141b/cyclohexane

R290/cyclopentane, R290/hexane,

R290/R600, R290/R601,

R600/cyclopentane, R600/hexane,

R600/R601, R601/cyclopentane,

R601/hexane, cyclopentane/hexane

R14/R23/R30, R14/R23/R236fa,

R14/R23/R245fa, R14/R23/R601
Analysis based on net

power output and cycle

efficiency

Experimental and

numerical analyses

Diesel engine at various

operating conditions

Diesel engine at various

operating conditions

Dual-loop power cycle configuration

Analysis based on cycle efficiencies

Analysis based on net power output

Analysis of subcritical and transcritical power cycle configurations

based on exergy

efficiency

Design and

optimization 


\section{* LNG heat sink.}

$\diamond$ Expander capacity.

$\ddagger$ Working fluid condenser outlet temperature. 
Hærvig et al. [38] proposed some general guidelines for selection of optimal working fluids for an ORC for WHR applications. The guidelines included the analysis of both pure and mixed working fluids for a wide range of operating conditions. With regards to mixtures, the guidelines suggested that the optimal compositions of the mixtures are those where the critical temperature of the mixture is approximately $30{ }^{\circ} \mathrm{C}$ to $50{ }^{\circ} \mathrm{C}$ lower than the heat source temperature, and the temperature glide during condensation is close to the temperature rise of the cooling source. Oyewunmi et al. [39] analysed the use of the SAFT-VR Mie equation of state for estimating the thermodynamic properties of pure and mixed working fluids. The results indicated that the use of pure fluids generally resulted in cycles with higher net power outputs and lower specific costs among the compared alternatives. The use of mixtures was however found to be beneficial in operating conditions with limited availability of the cooling medium or in cogeneration applications. Li et al. [40] evaluated the potential of using zeotropic mixtures as working fluids in ORC power systems for WHR applications. The results suggested that the ORCs with mixtures operated with higher levelized costs of electricity (LCOE) than the ORCs with pure fluids. Mondejar and Thern [41] analysed the use of isentropic mixtures in ORC power systems for the utilization of low to medium temperature industrial waste heat. The use of isentropic mixtures presents the possibility to minimize the need for recuperation and superheating, two issues common with using dry and wet working fluids, respectively. The results indicated $15 \%$ to $35 \%$ higher net power output with the ORC using isentropic mixtures as compared with the corresponding pure components.

Xiao et al. [42] presented a multi-objective optimization of evaporation and condensation temperatures for subcritical ORCs using pure or mixed working fluids. The optimization objectives were to simultaneously minimize the specific investment cost (i.e. the ratio of the total capital investment cost to the net power output from the plant) and the ratio of the total rate of exergy destruction to the exergy drop of the exhaust gas while supplying heat to the ORC working fluid. The results indicated that the performance of the mixed working fluids was not always better than that of the pure fluids, and that there are optimal values of evaporation and condensation temperatures for different working fluids. The effect of the 
different values of minimum pinch point temperature differences on the optimization function was also analysed. A similar analysis on the determination and matching of the pinch point temperature differences was also presented by Wu et al. [43]. Li and Dai [44] presented a thermoeconomic analysis of a mixture ORC for WHR applications. The performance indicators were net power output, the first and second law efficiencies, specific investment cost, the area of heat exchangers per unit of net power output, and the energy saving and emission reduction potentials. In general, the mixed working fluids were found to perform better than the pure working fluids from the economic perspective in both the basic ORC and the ORC with a recuperator. Kolahi et al. [45] presented the thermodynamic and economic analyses of an ORC unit for WHR from the exhaust gases of large diesel engines on an offshore platform. The mixture ORC was found to be thermodynamically superior to the pure fluid ORCs in terms of cycle efficiency. The recuperative ORC resulted in higher payback periods than the basic ORC because of higher specific investment cost due to the presence of an additional heat exchanger.

Le et al. [46] presented the thermodynamic and economic optimizations of subcritical ORCs for WHR applications. The study compared the performance of the ORC unit when using pure or mixture working fluids. The optimization objectives were to maximize the exergy efficiency and minimize the LCOE. The results suggested that the highest exergy efficiency and the minimum LCOE were shown by the configuration using pure R601. Feng et al. $[47,48]$ compared the performances of using pure or mixed working fluids in a WHR ORC power system. The comparisons were made on the basis of exergy efficiency and LCOE. The results indicated worse economic performance for the mixtures than the pure fluids. Weith et al. [49] analysed the performance of using siloxane mixtures for recovering heat from a high temperature exhaust gas. Since the temperature for the available exhaust gas was higher than the stable operating temperature of the siloxane mixtures, an intermediate thermal oil loop was used to transfer the heat from the exhaust gas to the ORC working fluid as shown in Fig. 5. The results suggested higher second law efficiency when using mixtures in both power-only and cogeneration modes, but with different compositions. However, the required heat exchanger areas were also larger for the mixtures than for the pure fluids. 


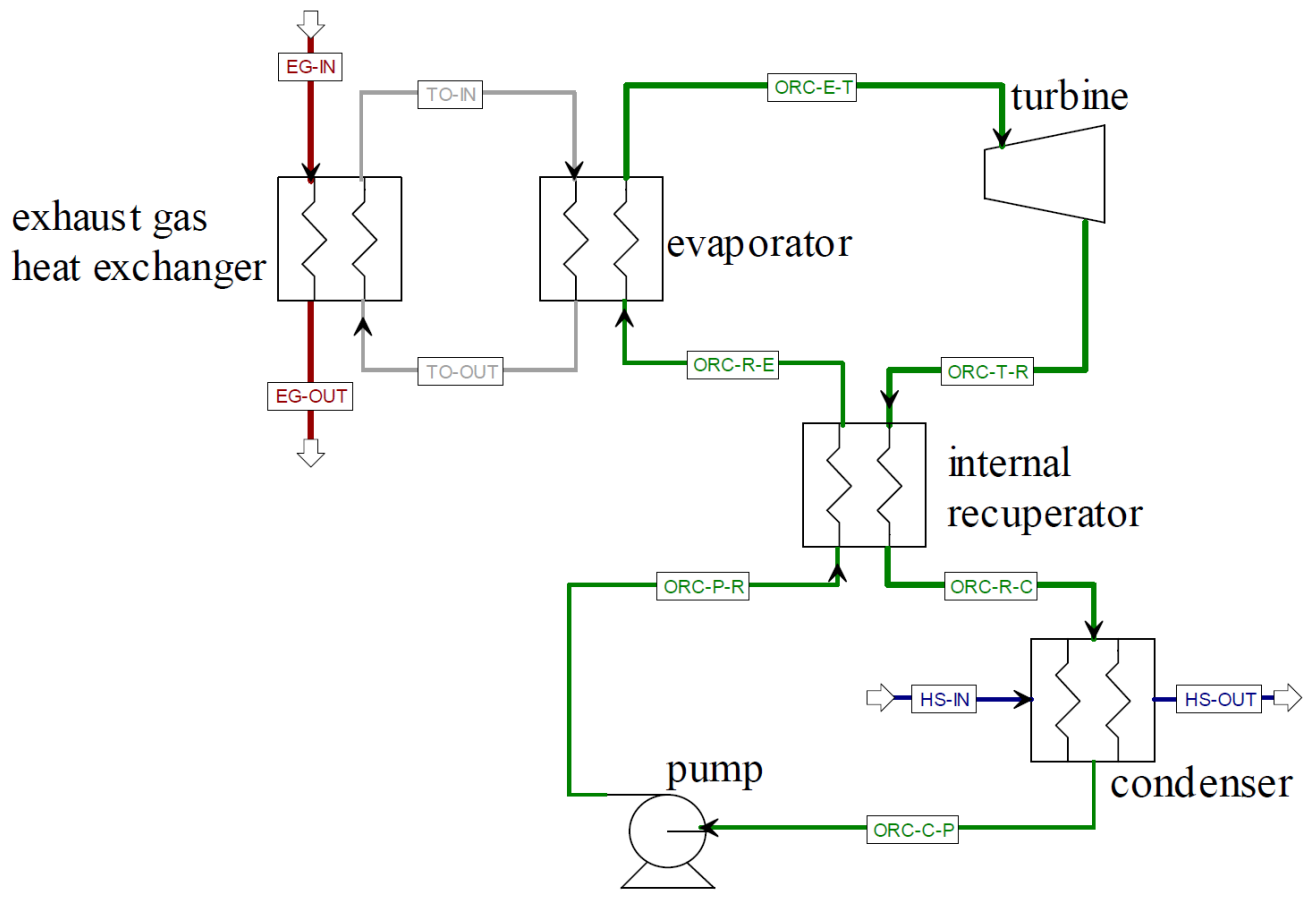

Figure 5: WHR ORC power system with an intermediate thermal oil loop [49]. In the layout, 'EG' is exhaust gas, 'TO' is thermal oil, 'HS' is the heat sink or cooling medium, and the ORC working fluid streams 'ORCE-T', 'ORC-T-R', 'ORC-R-C', 'ORC-C-P', 'ORC-P-R', and 'ORC-R-E' respectively represent the streams between the evaporator and the turbine, the turbine and the recuperator, the recuperator and the condenser, the condenser and the pump, the pump and the recuperator, and the recuperator and the evaporator.

Heberle and Brüggemann [50] presented a thermoeconomic analysis of using pure fluids and zeotropic mixtures in an ORC power system for WHR. The results suggested that lower values for minimum pinch point temperature differences in the evaporator and higher values in condenser are better for more cost-effective designs. Among the compared fluids, pure R600a resulted in the configuration with the lowest specific investment costs, but the configuration with R600a/R601a resulted in the lowest LCOE.

Guo et al. [51] analysed the performance of an ORC power system for WHR from the flue gas from a pulverized coal-fired power plant. The results suggested that there is no optimal composition that could simultaneously result in the best for all the performance indicators (i.e. first law efficiency, heat exchanger area, mass flow rate, volumetric flow rate, etc.) The results also indicated that the mixture composition which best matched the heat 


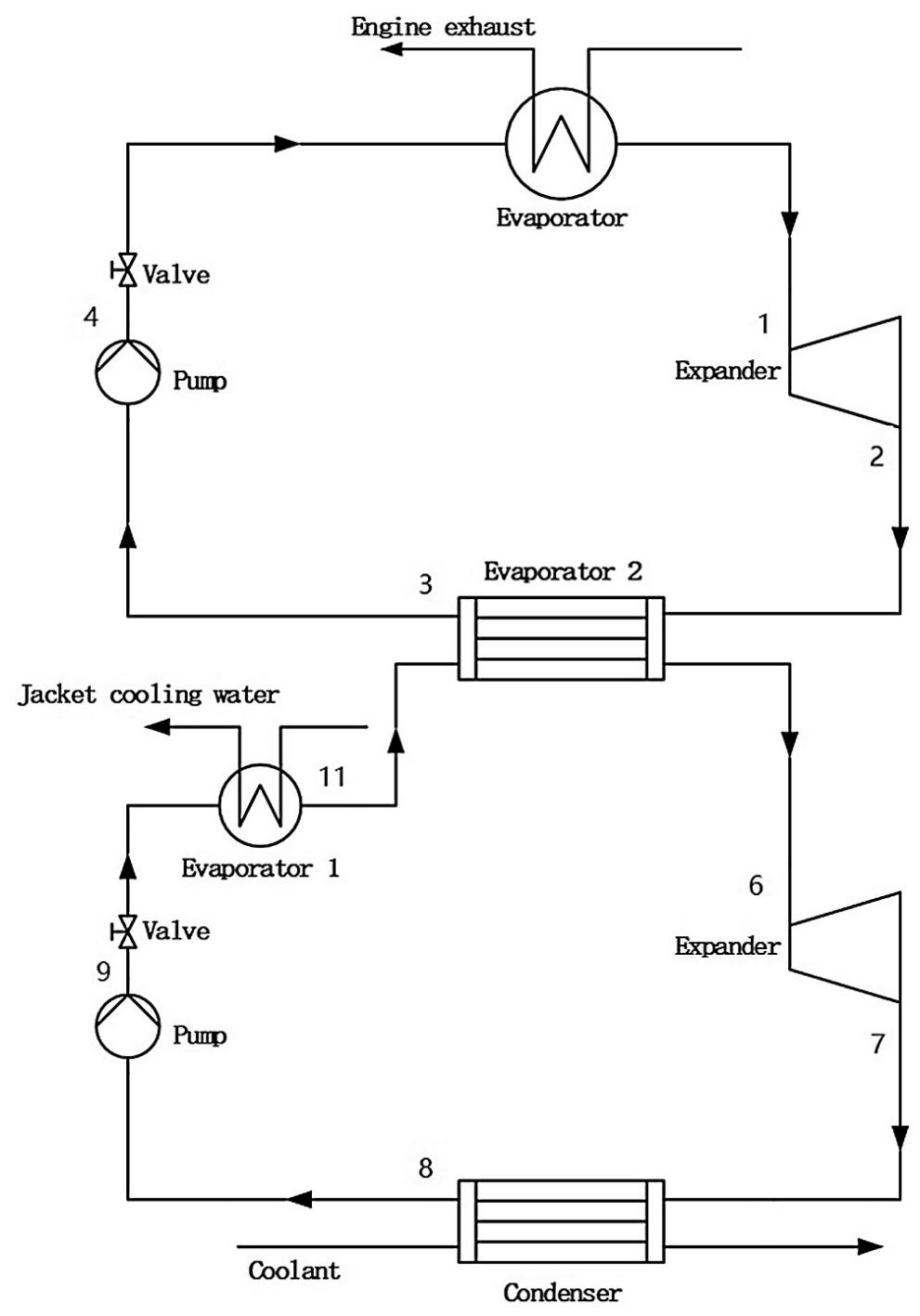

Figure 6: Dual-loop WHR plant with two bottoming cycles [58].

sink temperature profile resulted in the highest efficiency, while the composition that best matched the heat source temperature profile resulted in the lowest degree of superheat. The performance of an ORC unit using the mixture R416a was analysed for WHR from the exhaust gases from a compressed natural gas (CNG) engine [52] and a diesel engine [53]. A comparison was also made with the performance using some pure fluids [53]. Among the compared fluids for the diesel engine exhaust WHR, pure R600 resulted in the best WHR efficiency. Zhang et al. [54] analysed the performance of using pure and zeotropic mixture working fluids in an ORC power system with a recuperator for WHR from a diesel engine. 
The mixture R245fa/R601a resulted in higher net power output and cycle efficiency than pure R245fa. Jung et al. [55] presented the results from an experimental and numerical analyses of a mixture ORC. The heat source was the exhaust gas from a $30 \mathrm{~kW}$ gas turbine.

Yang et al. $[56,57]$ analysed the use of zeotropic mixtures for WHR from the exhaust of a temperature of the working fluid was significantly lower than the heat source temperature. Lee et al. [62] presented the design and optimization of a mixture ORC with a liquefied natural gas (LNG) heat sink. The performance of ternary fluid mixtures was analysed in 
this study.

\subsection{Other studies}

The studies presented in this section have been conducted assuming a generic heat source for a wide range of heat source temperatures (between around $25^{\circ} \mathrm{C}$ and $300{ }^{\circ} \mathrm{C}$ ) and plant capacities (between around $1 \mathrm{~kW}$ and 7.5 MW). The various mixtures have been evaluated based on energy, exergy, and economic analyses. Various atypical plant configurations such as the split-cycle, cascade power cycle, power cycle with pool boiling, and power cycle with partial evaporation have also been investigated. The simultaneous optimization of the power cycle with the working fluid composition has also been proposed. Table 4 shows an overview of these generic studies with their details presented in the following text. In the studies where comparisons were made between the use of pure fluids and fluid mixtures, Table 4 presents the details corresponding to the mixture analysis. 
Table 4: Studies with generic ORC power systems. $T_{\mathrm{hs}}$ is the heat source temperature and $T_{\mathrm{cs}}$ is the cooling medium temperature. A '-' instead of the value indicates unavailable data.

\begin{tabular}{|c|c|c|c|c|c|}
\hline Reference & $T_{\mathrm{hs}}\left({ }^{\circ} \mathrm{C}\right)$ & $T_{\mathrm{cs}}\left({ }^{\circ} \mathrm{C}\right)$ & Capacity $(\mathrm{kW})$ & Considered mixtures & Remarks \\
\hline Chys et al. [63] & $150-250$ & $25-35$ & $109.5-293.1$ & $\begin{array}{l}\text { Various mixture combinations of R245fa, } \\
\text { R364mfc, R600a, R601, R601a, hexane, } \\
\text { cyclohexane, and isohexane, and of MM } \\
\text { and MDM }\end{array}$ & $\begin{array}{l}\text { Comparison of } \\
\text { mixtures between low } \\
\text { and high heat supply } \\
\text { temperatures }\end{array}$ \\
\hline $\begin{array}{l}\text { Aghahosseini and } \\
\text { Dincer [64] }\end{array}$ & $150-200$ & $25^{\ddagger}$ & 100 & $\mathrm{R} 404 \mathrm{a}, \mathrm{R} 407 \mathrm{c}$ & $\begin{array}{l}\text { Energy and exergy } \\
\text { analyses }\end{array}$ \\
\hline $\begin{array}{l}\text { Lecompte } \\
\text { et al. }[65]\end{array}$ & $120-160$ & 20 & $1570-1980$ & $\begin{array}{l}\text { R245fa/R365mfc, R245fa/R601, } \\
\text { R600a/R601a, R601/hexane, } \\
\text { R601a/hexane, R601a/cyclohexane, } \\
\text { R601a/isohexane }\end{array}$ & Exergy analysis \\
\hline $\begin{array}{l}\text { Zhao and } \\
\text { Bao }[66]\end{array}$ & $125-185$ & 20 & $85-360$ & $\begin{array}{l}\text { R227ea/R236ea, R227ea/R236fa, } \\
\text { R227ea/R245ca, R227ea/R245fa, } \\
\text { R236ea/R236fa, R236ea/R245ca, } \\
\text { R236ea/R245fa, R236fa/R245ca, } \\
\text { R236fa/R245fa, R245ca/R245fa }\end{array}$ & $\begin{array}{l}\text { Analysis based on net } \\
\text { power output }\end{array}$ \\
\hline Luo et al. [67] & $120-280$ & 15 & $18-153$ & $\begin{array}{l}\text { Binary mixture combinations of various } \\
\text { pure fluids from the REFPROP database }\end{array}$ & $\begin{array}{l}\text { Low global warming } \\
\text { potential fluids }\end{array}$ \\
\hline Wu et al. [68] & 120 & 25 & $4100-5100$ & $\begin{array}{l}\text { RC318/R245fa, R227ea/R245fa, } \\
\text { R245fa/R600 }\end{array}$ & $\begin{array}{l}\text { Thermal and economic } \\
\text { analysis }\end{array}$ \\
\hline
\end{tabular}




\begin{tabular}{|c|c|c|c|c|c|}
\hline Xi et al. [69] & $100-180$ & $35^{\ddagger}$ & $30-250$ & $\begin{array}{l}\text { R245fa/R601, R245fa/R601a, } \\
\text { R245fa/butene, R245fa/cisbutene }\end{array}$ & $\begin{array}{l}\text { Economic evaluation } \\
\text { and optimization }\end{array}$ \\
\hline $\begin{array}{l}\text { Andreasen } \\
\text { et al. [70] }\end{array}$ & $90-120$ & 15 & $400-1500$ & $\begin{array}{l}\text { Binary mixture combinations of various } \\
\text { pure fluids from the REFPROP database }\end{array}$ & $\begin{array}{l}\text { Generic methodology } \\
\text { with working fluid as } \\
\text { optimization parameter }\end{array}$ \\
\hline $\begin{array}{l}\text { Andreasen } \\
\text { et al. [71] }\end{array}$ & 90 & 15 & $50-600$ & R134a/R32 (0.35/0.65 mole fraction) & $\begin{array}{l}\text { Multi-objective } \\
\text { optimization }\end{array}$ \\
\hline $\begin{array}{l}\text { Deethayat } \\
\text { et al. [72] }\end{array}$ & 115 & 27 & $46-50$ & $\mathrm{R} 152 \mathrm{a} / \mathrm{R} 245 \mathrm{fa}$ & $\begin{array}{l}\text { Analysis based on first } \\
\text { and second law } \\
\text { efficiencies }\end{array}$ \\
\hline $\begin{array}{l}\text { Deethayat } \\
\text { et al. [73] }\end{array}$ & $80-130^{\dagger}$ & $25-40^{\ddagger}$ & 16 & $\begin{array}{l}\text { R152a/R245ca, R152a/R245fa, } \\
\text { R227ea/R245ca, R227ea/R245fa, } \\
\text { R236ea/R245ca, R236ea/R245fa }\end{array}$ & $\begin{array}{l}\text { Analysis based on } \\
\text { figure of merit }\end{array}$ \\
\hline Dong et al. [74] & $250-300$ & $30-80$ & $4.8-15.2$ & $\mathrm{MDM} / \mathrm{MM}$ & $\begin{array}{l}\text { Analysis based on first } \\
\text { law efficiency }\end{array}$ \\
\hline Guo et al. [75] & $95-200$ & $20-32$ & - & $\begin{array}{l}\text { Binary mixture combinations using } \\
\text { R134a, R227ea, R236ea, R245fa, R290, } \\
\text { R600, R600a, R601, and R601a }\end{array}$ & $\begin{array}{l}\text { Comparison of pure } \\
\text { and mixture working } \\
\text { fluids }\end{array}$ \\
\hline $\begin{array}{l}\text { Collings } \\
\text { et al. [76] }\end{array}$ & 100 & - & 1000 & $\mathrm{R} 134 \mathrm{a} / \mathrm{R} 245 \mathrm{fa}$ & $\begin{array}{l}\text { Dynamic analysis with } \\
\text { air-cooled condenser }\end{array}$ \\
\hline Yoon et al. [77] & 26 & 5 & 20 & $\mathrm{R} 152 \mathrm{a} / \mathrm{R} 32$ & $\begin{array}{l}\text { Power cycle } \\
\text { configuration with } \\
\text { vapour-liquid ejector }\end{array}$ \\
\hline
\end{tabular}


Kim et al. [78] 25-85 - $161^{*}$

Andreasen

$90-120$

15

et al. [79]

Chen et al. [80]

$120-200$

$20-30$

Dai et al. [81]

$120-240^{\dagger} \quad 10-60^{\ddagger}$

$10-50$

$\stackrel{\oplus}{\bullet}$ Pan et al. [82]

Rajabloo

et al. [83]

Liu et al. [84]

Zhou et al. [85]

Abadi et al. [86

Wang et al. [87]
140-300

20-70

29-36

120

200

$167 / 300$

$47 / 90^{\ddagger}$

$1300-3100$

$3.5-6.5$

80-120

25

90-135
R14/R170, R14/R290, R14/R600,

R14/R600a, R170/R600, R170/R600a,

R170/R601, R290/R601, R50/R600,

R50/R600a, R50/R601

Binary mixture combinations using

R290, R600, R600a, R601, and R601a

Binary mixture combinations of several

refrigerants

$\mathrm{CO}_{2} / \mathrm{R} 1234 \mathrm{yf}, \mathrm{CO}_{2} / \mathrm{R} 1234 z e$,

$\mathrm{CO}_{2} / \mathrm{R} 1270, \mathrm{CO}_{2} / \mathrm{R} 134 \mathrm{a}, \mathrm{CO}_{2} / \mathrm{R} 152 \mathrm{a}$,

$\mathrm{CO}_{2} / \mathrm{R} 161, \mathrm{CO}_{2} / \mathrm{R} 32$

$\mathrm{CO}_{2} / \mathrm{R} 290$

Various binary mixture combinations

using either hydrocarbons or siloxanes

R600/R601, R600/R601a, R600a/R601,

R600a/R601a, octane/decane,

nonane/decane, $\mathrm{MDM} / \mathrm{MD}_{2} \mathrm{M}$

R227ea/R245fa

R134a/R245fa (0.4/0.6 mole fraction)

R600a/R601a
Cascade power cycle

configuration

Orgaic split-cycle

Transcritical ORC

power system

Transcritical ORC

power system

Transcritical ORC

power system

Pool boiling feasibility

analysis

Effect of condensation

temperature glide

Partial evaporation

Experimental analysis

Experimental analysis 


\begin{tabular}{lllll} 
Molina-Thierry & $90-150$ & 30 & $400-7500$ & $\begin{array}{l}\text { Study on identification of mixture } \\
\text { components and composition }\end{array}$ \\
$\begin{array}{l}\text { and Flores- } \\
\text { Tlacuahuac [88] }\end{array}$ & & Simultaneous mixture & cycle design \\
\hline
\end{tabular}

* LNG heat sink.

$\diamond$ Expander capacity.

$\dagger$ Expander inlet temperature.

$\ddagger$ Working fluid condenser outlet temperature. 
Chys et al. [63] assessed the potential of using zeotropic mixtures in ORC power systems. The results indicated that the advantage of using zeotropic mixtures as working fluids is more prominent with low temperature heat sources than with high temperature ones. Aghahosseini and Dincer [64] presented the results from a comparative analysis between using pure and mixed working fluids in an ORC power system through energy and exergy analyses. Lecompte et al. [65] also presented the exergy analysis of using zeotropic mixtures as working fluids in subcritical ORCs. The optimization objective was to maximize the second law efficiency of the power cycle. The results suggested an improvement in the second law efficiency with mixed working fluids as compared with the pure fluids. Zhao and Bao [66] presented a thermodynamic analysis of a mixture ORC. The results indicated at the presence of an optimal evaporating temperature resulting in the highest net power output. Luo et al. [67] evaluated the use of low global warming potential fluids in ORC power systems. The performance of both pure fluids and their mixtures was investigated. Wu et al. [68] performed thermal and economic analyses of mixture ORCs. The results suggested that the use of mixtures results in higher first and second law efficiencies and net power output from the plant than the use of pure working fluids, but at the same time the mixtures have a lower economic performance because of larger heat exchanger area requirements. The optimal mixture compositions were those where the temperature glide of the mixture was the closest to the temperature rise of the cooling water in the condenser. $\mathrm{Xi}$ et al. [69] presented an economic evaluation and optimization of an ORC power system with several mixtures using R245fa as a flame retardant. The mixtures were found to result in lower electricity production costs than their corresponding pure fluid components, mainly because of the lower capital investment cost for the evaporator.

Andreasen et al. $[70,71]$ optimized the ORC power systems using pure and mixed working fluids for the utilization of low grade heat. A generic methodology was proposed where the working fluid was included as an optimization parameter in the numerical model. The optimization results indicated that the use of mixtures could increase the net power output from the plant [70]. In the multi-objective optimization with the simultaneous maximization of net power output and the minimization of ORC unit investment cost, the mixture ORC 
faired better than the ORCs with the constituent pure fluids as the cycle working fluid with $3.4 \%$ higher net power output at the same total investment cost [71]. Deethayat et al. [72, 73] presented the results from a performance analysis of mixture ORCs with and without a recuperator based on first and second law efficiencies [72] and figure of merit [73]. Dong et al. [74] analysed the use of zeotropic mixtures in a high temperature ORC power system with a recuperator. The results demonstrated that the use of zeotropic mixtures resulted in higher first law efficiency than the constituent pure fluids. Guo et al. [75] presented the comparison of various pure and mixed working fluids for the utilization of low temperature heat sources. The results indicated that the mixed working fluids performed better with lower heat source temperature and higher temperature gradients for both the heat source and the heat sink. Pure fluids performed better when the conditions were reversed.

Collings et al. [76] dynamically analysed a mixture ORC power system with an air-cooled condenser. The ORC unit included an additional composition control system which allowed it to operate with varying working fluid composition to suit the ambient conditions. Yoon et al. [77] presented the performance analysis of a mixture power cycle using a vapour-liquid ejector and two expanders for ocean thermal energy conversion (OTEC) applications. The optimal fluid composition for maximum cycle efficiency was determined. For a similar application, Kim et al. [78] presented the design and optimization of a cascade ORC power system with sea water as the heat source and LNG as the heat sink. Andreasen et al. [79] presented the design and optimization of an organic split-cycle as shown in Fig. 7 with an improved boiling process. The results suggested that the use of the organic split-cycle resulted in a higher net power output for lower values of heat source temperature, but this performance improvement came at the cost of significant increase in the cycle complexity. Chen et al. [80] analysed a transcritical mixture ORC for the conversion of low grade heat into power. The transcritical ORC with mixtures resulted in $10 \%$ to $30 \%$ higher cycle efficiency values than the subcritical ORC. Dai et al. [81] analysed transcritical power cycles with mixtures including $\mathrm{CO}_{2}$ as one of the components. A similar cycle was also studied by Pan et al. [82] where the optimal values of net power output and cycle efficiency at various supercritical heating pressures were presented. 


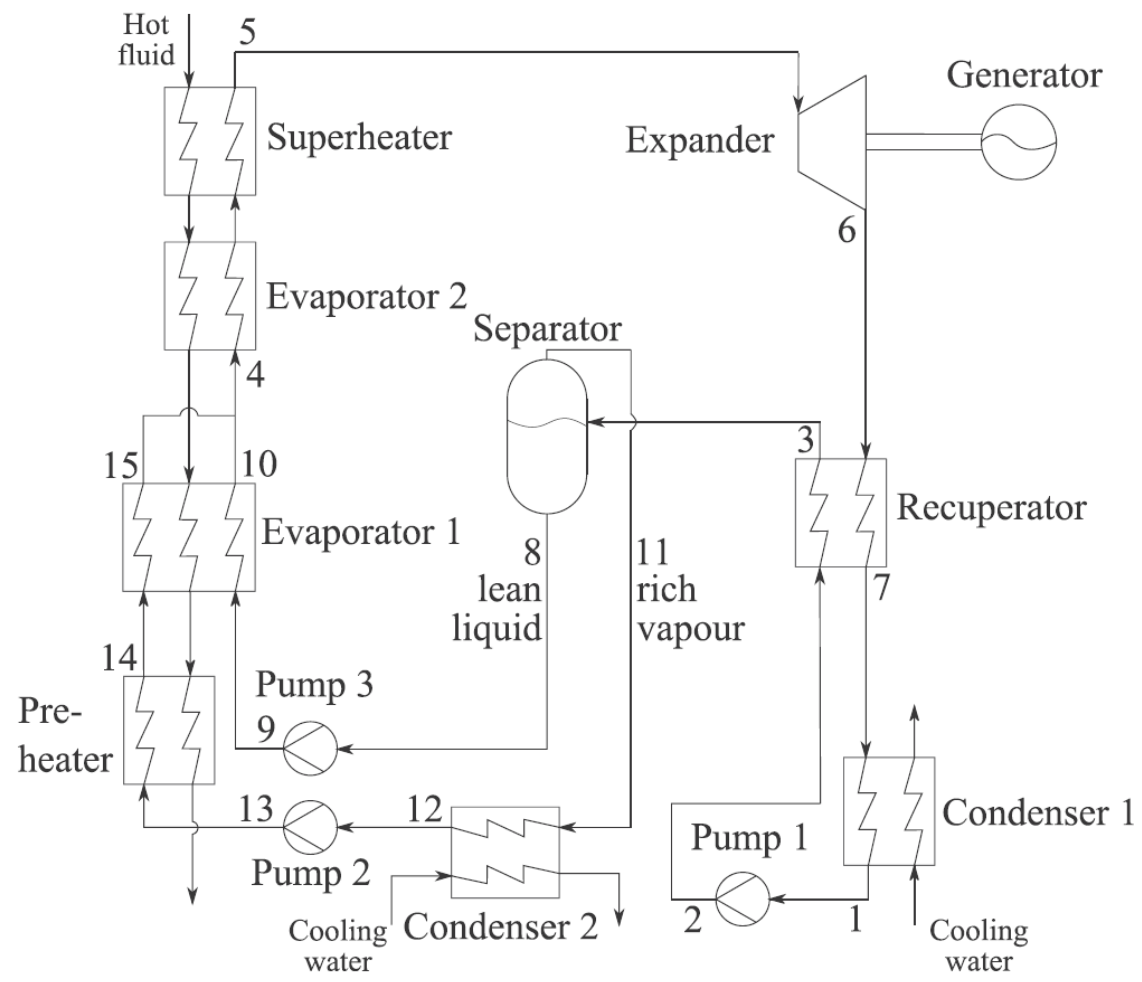

Figure 7: Organic split-cycle for mixtures [79].

Among other studies, Rajabloo et al. [83] assessed the feasibility of using pool boiling with mixture ORCs for geothermal power generation $\left(T_{\mathrm{hs}}=167^{\circ} \mathrm{C}\right)$ and biomass combustion based power generation $\left(T_{\mathrm{hs}}=300{ }^{\circ} \mathrm{C}\right)$. The results suggested that the plant configuration with pool boiling showed lower, but comparable thermodynamic performance as the plant configuration with a once-through evaporator. However, since the plant performance did not significantly deteriorate with pool boiling, it could be considered as a feasible alternative because of easier control. Liu et al. [84] analysed the effect of condensation temperature glide on the performance of mixture ORCs with geothermal water or biomass as the heat source. A method to determine the optimal condensation pressure was presented. Zhou et al. [85] analysed an ORC with partial evaporation, i.e. the expander received a stream in two-phase flow. The results indicated that the optimized partial evaporation ORC configuration produced $24.7 \%$ more power than the subcritical ORC configuration. Abadi et al. [86] presented the experimental study of a mixture ORC. The results suggested that a higher net 
power output by about $50 \%$ to $75 \%$ was achievable using the mixture as compared with the pure working fluid for heat source temperatures between $80^{\circ} \mathrm{C}$ and $100{ }^{\circ} \mathrm{C}$. In another discussed in this paper.

\subsection{Ammonia-water Rankine cycle power systems}

The studies with the ammonia-water Rankine cycle power systems have been conducted typically for moderate values of heat source temperature (between around $120{ }^{\circ} \mathrm{C}$ and $330{ }^{\circ} \mathrm{C}$ ) 
and a wide range of plant capacities (between around $30 \mathrm{~kW}$ and $1.3 \mathrm{MW}$ ). In addition to the usual energy and exergy analyses, the publications also included parametric studies, exergoeconomic analysis, and thermodynamic optimizations. Table 5 shows an overview of these studies while their details are presented in the following text. An ammonia-water Rankine cycle with and without a recuperator is shown in Fig. 8. In the studies where comparisons were made between the ammonia-water Rankine cycle and other power cycles, Table 5 presents the details corresponding to the ammonia-water Rankine cycle.

Table 5: Studies with ammonia-water Rankine cycle power systems. $T_{\mathrm{hs}}$ is the heat source temperature and $T_{\mathrm{cs}}$ is the cooling medium temperature. A '-' instead of the value indicates unavailable data.

\begin{tabular}{|c|c|c|c|c|c|}
\hline Reference & Application & $T_{\mathrm{hs}}\left({ }^{\circ} \mathrm{C}\right)$ & $T_{\mathrm{cs}}\left({ }^{\circ} \mathrm{C}\right)$ & Capacity (kW) & Remarks \\
\hline $\begin{array}{l}\text { Mohammadkhani } \\
\text { et al. [92] }\end{array}$ & Generic & 180 & 15 & - & $\begin{array}{l}\text { Exergoeconomic } \\
\text { analysis }\end{array}$ \\
\hline $\begin{array}{l}\text { Koroneos and } \\
\text { Rovas [93] }\end{array}$ & Geothermal & 120 & 20 & $737.5^{\diamond}$ & Exergy analysis \\
\hline Kim et al. $[94,95]$ & WHR & 180 & 15 & - & $\begin{array}{l}\text { Energy and exergy } \\
\text { analyses, variation } \\
\text { in working fluid } \\
\text { composition }\end{array}$ \\
\hline Kim et al. $[96,97]$ & WHR & 200 & $-20-40^{*, \ddagger}$ & 32 & $\begin{array}{l}\text { Energy and exergy } \\
\text { analyses }\end{array}$ \\
\hline Wang et al. [98] & WHR & 200 & $-159.35^{*}$ & 389.4 & $\begin{array}{l}\text { Parametric study } \\
\text { and thermodynamic } \\
\text { optimization }\end{array}$ \\
\hline $\begin{array}{l}\text { Pierobon and } \\
\text { Rokni [99] }\end{array}$ & WHR & $250^{\dagger}$ & $25^{\ddagger}$ & $1130-1290$ & $\begin{array}{l}\text { Thermodynamic } \\
\text { analysis }\end{array}$ \\
\hline $\begin{array}{l}\text { Khankari and } \\
\text { Karmakar [100] }\end{array}$ & WHR & $121-198^{\dagger}$ & 25 & $412-832$ & $\begin{array}{l}\text { Parametric study } \\
\text { and thermodynamic } \\
\text { analysis }\end{array}$ \\
\hline
\end{tabular}




$\begin{array}{llllll}\text { Wang et al. [101] } & \text { WHR } & 327 & 5-55^{\ddagger} & - & \text { Feasibility study of } \\ & & & \text { using } \\ & & & \text { ammonia-water } \\ & & & & \text { power cycles } \\ & & & & \text { Parametric study } \\ \text { Mohtaram } & \text { WHR } & 304 & 25 & - & \\ \text { et al. }[102] & & & & & \end{array}$

* LNG heat sink.

$\diamond$ Expander capacity.

$\dagger$ Expander inlet temperature.

$\ddagger$ Working fluid condenser outlet temperature.

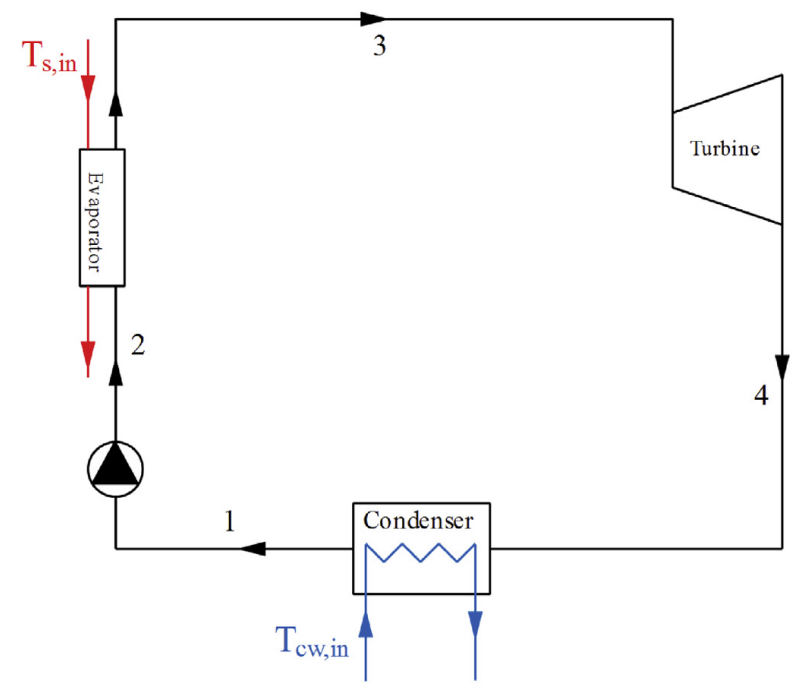

(a) Without recuperator.

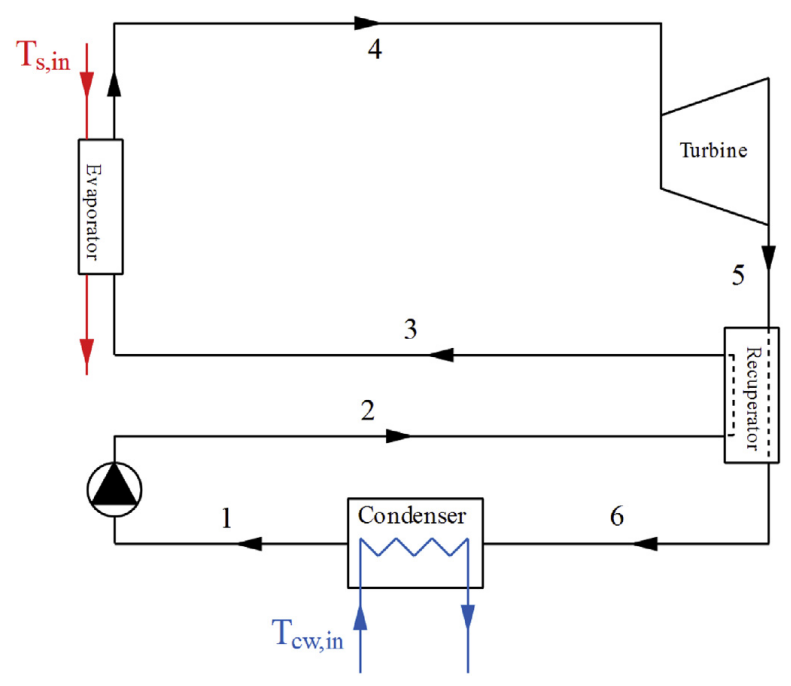

(b) With recuperator.

Figure 8: Ammonia-water Rankine cycle [92]. $T_{\mathrm{s}, \text { in }}$ is the heat source inlet temperature and $T_{\mathrm{cw} \text {,in }}$ is the cooling medium inlet temperature.

Mohammadkhani et al. [92] presented an exergoeconomic comparison between ammonia-water Rankine cycle power systems with and without a recuperator. The results indicated that unlike the results from the energy and exergy analyses, the ammonia-water Rankine cycle power system without the recuperator performs better in an exergoeconomic analysis than the ammonia-water Rankine cycle power system with a recuperator. Among 
various cycle parameters, the working fluid composition was found to affect the exergoeconomic performance of the power cycles most significantly. The results also indicated that with increasing ammonia mass fraction in the working fluid, the rates of exergy destruction in the heat exchangers increased because of the larger mean temperature difference. Koroneos and Rovas [93] presented an exergy analysis of a geothermal power plant where the fluid at the geothermal turbine outlet is used as the heat source to the ammonia-water mixture in an ammonia-water Rankine cycle unit. Kim et al. [94, 95] presented a comparison between the ammonia-water Rankine cycles with and without a recuperator through energy and exergy analyses. The effect of varying the working fluid composition on the thermodynamic performance of the cycles was also examined. The results indicated that the ammonia-water Rankine cycle with a recuperator resulted in better thermal and exergy efficiencies than the ammonia-water Rankine cycle without the recuperator.

A few studies have also investigated the performance of an ammonia-water Rankine cycle power system with heat rejection to a heat sink using LNG as the cooling medium. Kim et al. $[96,97]$ presented the energy and exergy analyses of a combined ammonia-water Rankine and LNG bottoming cycle power plant as shown in Fig. 9. In this plant, the heat source for the ammonia-water Rankine cycle is waste heat, while the heat rejection takes place in a condenser with LNG as the cooling medium. The results indicated that the cycle performance is most significantly influenced by the working fluid composition. Wang et al. [98] presented the effects of varying the turbine inlet pressure, temperature, and ammonia mass fraction, and the minimum pinch point and the approach temperature differences in the heat recovery vapour generator on the cycle performance. A thermodynamic optimization for the ammonia-water Rankine cycle unit with LNG heat sink was performed with three objective functions: maximize exergy efficiency and minimize the total heat transfer capability and the turbine size parameter. Pierobon and Rokni [99] presented an analysis of a hybrid plant with a gasification system, solid oxide fuel cell, and an ammonia-water Rankine cycle unit with a recuperator. The gasifier converts wood chips to syngas which is then used to operate the fuel cell. The excess heat from the fuel cell serves as the heat source for the ammonia-water Rankine cycle unit. 


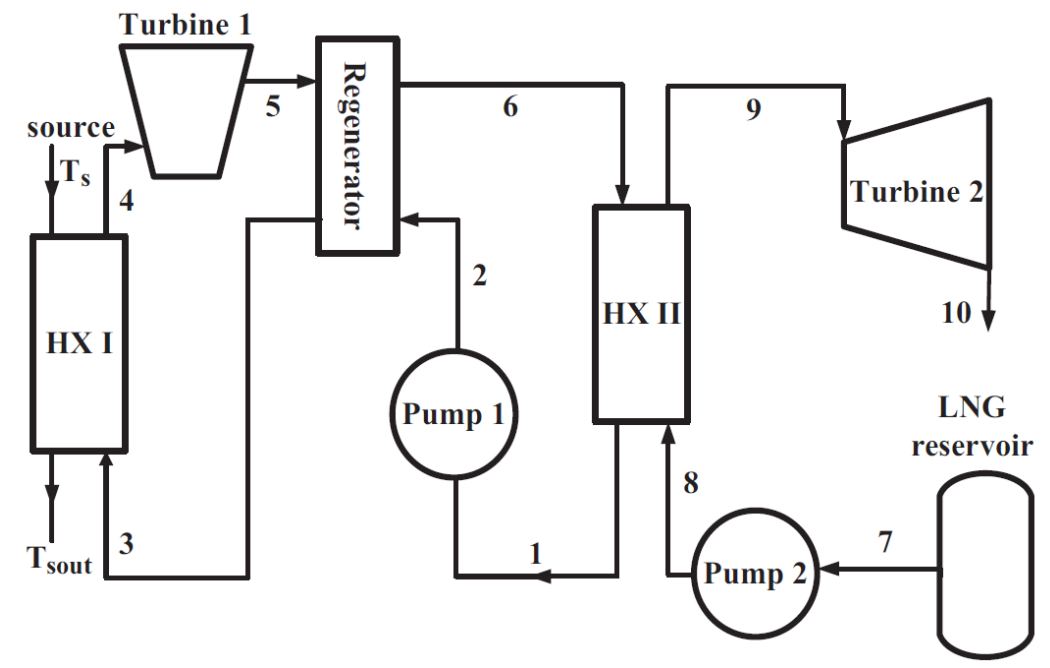

Figure 9: Ammonia-water Rankine cycle unit with a bottoming LNG power cycle [96]. $T_{\mathrm{s}}$ is the heat source inlet temperature and $T_{\text {sout }}$ is the heat source outlet temperature from the heat exchanger HX I.

Khankari and Karmakar [100] presented an analysis of possible power generation from coal mill rejection. Various turbine inlet conditions were examined in the study. The results suggested that the payback period for installing such a power generation system would be about 5.5 years with $80 \%$ plant availability factor and $100 \%$ plant load factor. Wang et al. [101] developed a code for the estimation of the thermodynamic properties of the ammonia-water mixture and used this code to assess the possibility of using an ammonia-water Rankine cycle in a pressurized water reactor nuclear power plant. A comparison was made between the performances of the ammonia-water Rankine cycles with and without a recuperator and a flash Kalina cycle. The results suggested that the flash Kalina cycle could attain a thermal efficiency of $34.8 \%$ but with a more complex cycle layout, whereas a slightly lower cycle efficiency of $31.2 \%$ may be attained with a much simpler ammonia-water Rankine cycle with recuperator. Momeni et al. [103] presented the results from the thermoeconomic optimization of a three stage combined cycle power plant with a gas turbine on top, a steam Rankine cycle in the middle, and an ammonia-water Rankine cycle at the bottom. The simultaneous maximization of the exergy efficiency and minimization of the total cost rate was the optimization objective. Mohtaram et al. [102] presented the results from the evaluation of the effect of varying the compressor pressure 
ratio in a combined cycle power plant with an ammonia-water Rankine cycle or a simple steam Rankine cycle as the bottoming cycle.

\subsection{Solar energy based Kalina cycle power systems}

The studies on solar energy based Kalina cycle power systems have been conducted with both low and high temperature Kalina cycle configurations, depending on the type of solar collectors. The plants have been investigated using energy and exergy analyses, parametric studies, and thermoeconomic optimizations. Table 6 shows an overview of these studies with their details presented in the following text. These include the use of a Kalina cycle unit with both non-concentrating and concentrating solar collectors. In the studies where comparisons were made between the Kalina cycle and other power cycles, Table 6 presents the details corresponding to the Kalina cycle.

Table 6: Studies with solar energy based Kalina cycle power systems. $T_{\mathrm{hs}}$ is the heat source temperature and $T_{\mathrm{Cs}}$ is the cooling medium temperature. A '-' instead of the value indicates unavailable data.

\begin{tabular}{|c|c|c|c|c|}
\hline Reference & $T_{\mathrm{hs}}\left({ }^{\circ} \mathrm{C}\right)$ & $T_{\mathrm{cs}}\left({ }^{\circ} \mathrm{C}\right)$ & Capacity (kW) & Remarks \\
\hline Sun et al. $[104,105]$ & $60-76$ & $4-4.5$ & - & $\begin{array}{l}\text { Energy and exergy analyses } \\
\text { and optimization }\end{array}$ \\
\hline $\begin{array}{l}\text { Shankar Ganesh and } \\
\text { Srinivas }[106]\end{array}$ & $130-150$ & 30 & - & $\begin{array}{l}\text { Parametric and cycle } \\
\text { configuration studies }\end{array}$ \\
\hline $\begin{array}{l}\text { Shankar Ganesh and } \\
\text { Srinivas }[107]\end{array}$ & $190-225$ & 25 & - & $\begin{array}{l}\text { Parametric study and exergy } \\
\text { analysis }\end{array}$ \\
\hline $\begin{array}{l}\text { Shankar Ganesh and } \\
\text { Srinivas [108] }\end{array}$ & 500 & $35^{\ddagger}$ & - & $\begin{array}{l}\text { Parametric study and exergy } \\
\text { analysis }\end{array}$ \\
\hline Ashouri et al. [109] & $90-108^{\dagger}$ & - & - & $\begin{array}{l}\text { Techno-economic analysis, } \\
\text { estimation of annual solar } \\
\text { fraction and LCOE }\end{array}$ \\
\hline $\begin{array}{l}\text { Boyaghchi and } \\
\text { Sabaghian [110] }\end{array}$ & 120 & 5 & $1800-2300$ & Multi-objective optimization \\
\hline Knudsen et al. [111] & $550^{\dagger}$ & 30 & - & Energy and exergy analyses \\
\hline
\end{tabular}




$\begin{array}{lllll}\text { Modi et al. }[112,113] & 450^{\dagger} & 20 & 25000^{\S} & \text { Feasibility study through } \\ & & & & \text { energy and exergy analyses } \\ \text { Modi et al. }[114-116] & 500^{\dagger} & 20 & 20000 & \text { Part-load performance } \\ & & & & \text { analysis, thermoeconomic } \\ & & & \text { optimization }\end{array}$

$\dagger$ Expander inlet temperature.

$\ddagger$ Working fluid condenser outlet temperature.

$\S$ Heat input to the power cycle.

Sun et al. [104, 105] presented the energy and exergy analyses and optimization of a solar-boosted Kalina cycle power system (KCS-11 layout). The use of compound parabolic collectors and an auxiliary superheater in order to increase the turbine inlet temperature was analysed for the climatic conditions of Japan. The use of compound parabolic collectors with a Kalina cycle power system was also studied by Wang et al. [117]. In their layout, they also had a thermal storage tank and an auxiliary heater as shown in Fig. 10. The Kalina cycle unit had two separators and the analysis was conducted for the climatic conditions of China. The results indicated that the net power output and the cycle efficiency were less sensitive to the turbine inlet temperature and an optimal turbine inlet pressure and basic solution ammonia mass fraction may be obtained depending on whether the net power output or the maximum cycle efficiency is the optimization objective. The presence of the thermal storage system enabled the plant to operate in a continuous and stable manner. Astaraei et al. [118] presented an analysis of a solar-driven Kalina cycle power system with an auxiliary heater for satisfying the electricity demands of high-rise buildings in Iran. Flat plat solar collectors were used in the investigated plant. The results suggested that in five provinces of Iran, the solar Kalina plant could generate more electricity than the potential demand.

Shankar Ganesh and Srinivas [106-108] presented an analysis of Kalina cycles with a parabolic trough solar field with different operating temperatures. For a low temperature operation, different positioning of the recuperators within the Kalina cycle was in- 


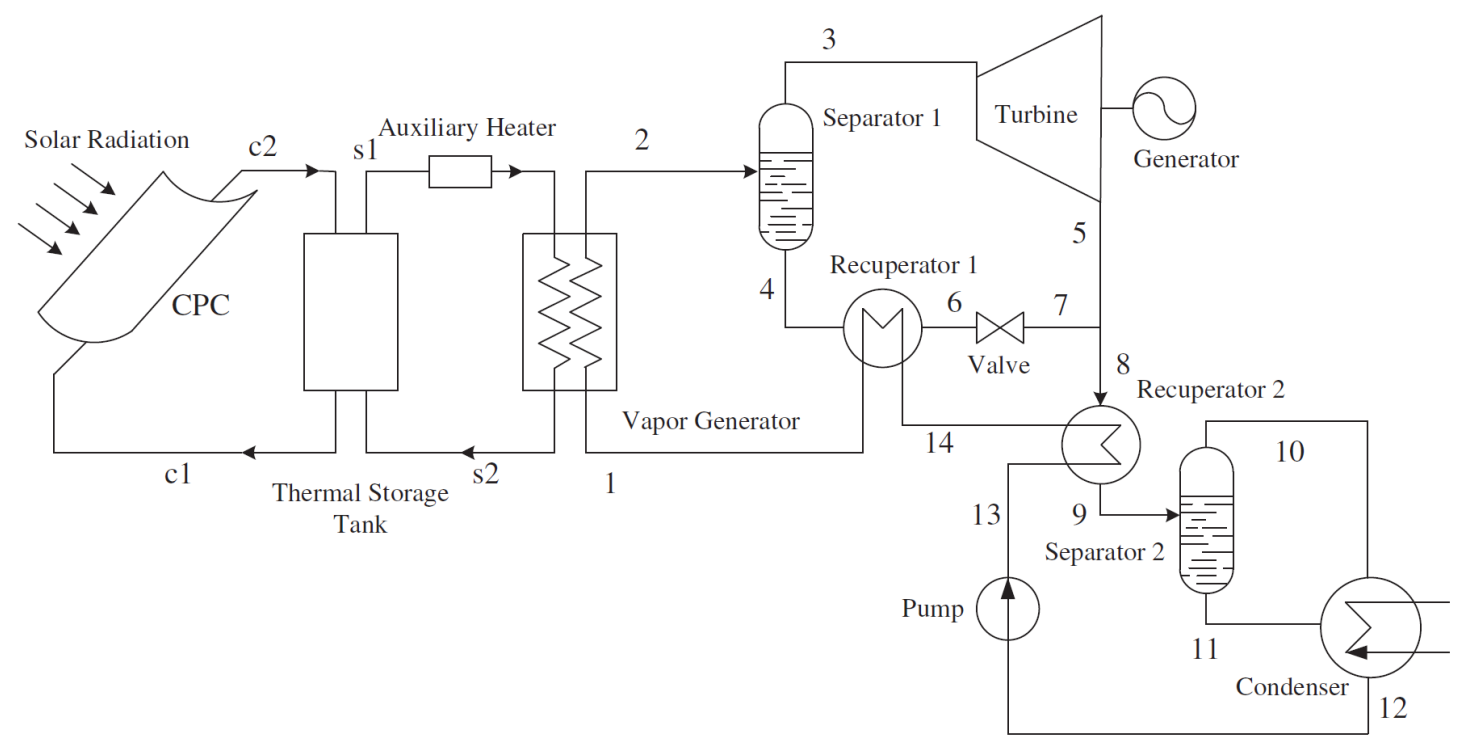

Figure 10: Low temperature solar energy based Kalina cycle power system [117]. 'CPC' implies compound parabolic collectors.

vestigated [106]. Exergy analysis was also conducted for the analysed Kalina cycle layouts $[107,108]$. Among the Kalina cycle components, the highest rates of exergy destruction were for the turbine and the heat recovery vapour generator. Ashouri et al. [109] presented a techno-economic assessment of a Kalina cycle unit operating with a parabolic trough solar field for the climatic conditions of Iran. The annual solar fraction and LCOE for the power plant were estimated along with the potential savings in the use of fossil fuel. The results suggested that the presence of thermal storage and an auxiliary heater reduced the temperature fluctuations in the Kalina cycle operation, and that the highest rates of exergy destruction occurred in the solar field and the vapour generator. Boyaghchi and Sabaghian [110] presented a multi-objective optimization of a Kalina cycle unit with parabolic trough solar field using the genetic algorithm. The three objectives for the optimization were the maximization of the energy efficiency and the exergy efficiency, and the minimization of the total capital investment cost. Among the considered decision variables, the evaporator outlet temperature influenced the results most significantly. 


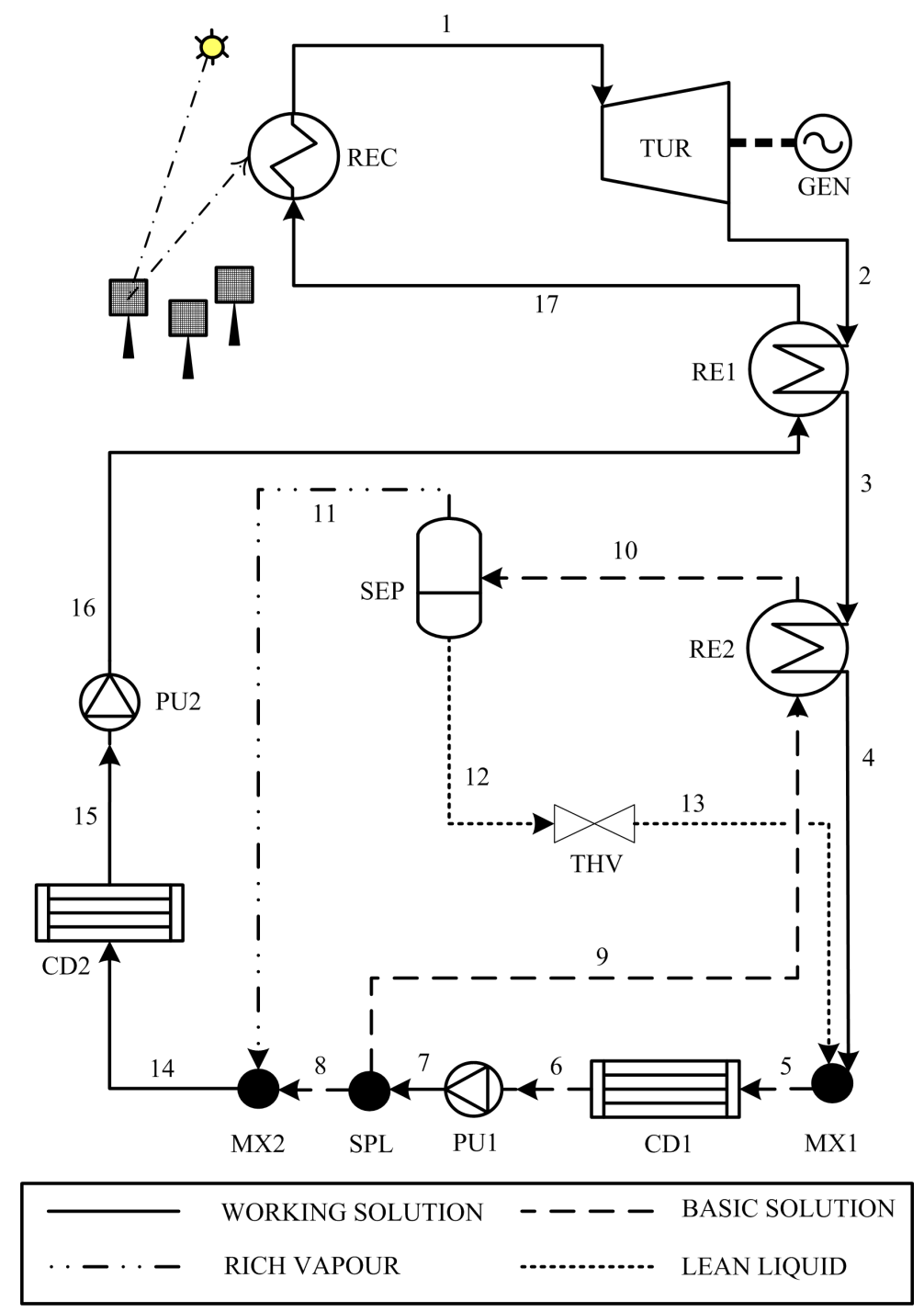

Figure 11: High temperature Kalina cycle $\mathrm{KC12}$ for a central receiver concentrating solar power plant with direct steam generation [114]. In the layout, REC is the receiver/boiler, TUR is the turbine, GEN is the generator, SEP is the vapour-liquid separator, RE* is the recuperator, $\mathrm{PU} *$ is the pump, $\mathrm{CD} *$ is the condenser, MX* is the mixer (where ' $*$ ' denotes the respective component number), SPL is the splitter, and THV is the throttling valve.

The layout for a high temperature Kalina cycle differs significantly from that of a low temperature Kalina cycle. An example of a Kalina cycle for a high temperature central receiver concentrating solar power plant with direct steam generation is shown in Fig. 11. Knudsen et al. [111] presented the energy and exergy analyses of a Kalina cycle unit with 
direct steam generation that could be operated with either a parabolic trough or a central receiver solar field. Modi et al. [112, 113] assessed the possibility of using a Kalina cycle unit in a central receiver concentrating solar power plant through energy and exergy analyses. The results indicated that the highest rate of exergy destruction in the power cycle occurs in the receiver/boiler. The study was continued with a full thermoeconomic optimization [114, 119] with the minimization of LCOE as the objective function by combining the detailed thermodynamic design [115] and the part-load models [116] in order to evaluate the cycle performance over a year. The results suggested that a Kalina cycle power system without storage cannot compete with the state-of-the-art steam Rankine cycle power system for high temperature solar power applications when considering both the thermodynamic and the economic aspects.

\subsection{Geothermal heat based Kalina cycle power systems}

The studies on geothermal heat based Kalina cycle power systems have been conducted with heat source temperatures between around $100{ }^{\circ} \mathrm{C}$ and $180{ }^{\circ} \mathrm{C}$ and for plant capacities between around $6 \mathrm{~kW}$ and $6.3 \mathrm{MW}$. The plants have been analysed based on their energy and exergy efficiencies, part-load performances, and economic feasibility. The performance of the Kalina cycle power systems have also been compared to that of the ORC power systems. Table 7 shows an overview of these studies with their details presented in the following text. In the studies where comparisons were made between the Kalina cycle and other power cycles, Table 7 presents the details corresponding to the Kalina cycle.

Table 7: Studies with geothermal heat based Kalina cycle power systems. $T_{\mathrm{hs}}$ is the heat source temperature and $T_{\mathrm{cs}}$ is the cooling medium temperature. A '-' instead of the value indicates unavailable data.

\begin{tabular}{lllll}
\hline Reference & $T_{\mathrm{hs}}\left({ }^{\circ} \mathrm{C}\right)$ & $T_{\mathrm{cs}}\left({ }^{\circ} \mathrm{C}\right)$ & Capacity $(\mathrm{kW})$ & Remarks \\
\hline Campos Rodríguez & 100 & 25 & $1444-1756$ & Exergy and economic \\
et al. $[120]$ & & & & analyses, comparison with \\
& & & & ORC power system \\
Walraven et al. [121] & $100-150$ & $15-30$ & - & Exergy analysis
\end{tabular}




\begin{tabular}{|c|c|c|c|c|}
\hline Li and Dai $[122]$ & $120-132$ & 17 & $139-200$ & $\begin{array}{l}\text { Thermoeconomic } \\
\text { performance analysis }\end{array}$ \\
\hline $\begin{array}{l}\text { Coskun } \\
\text { et al. [123, 124] }\end{array}$ & $140-180$ & 18 & $5900-6300$ & $\begin{array}{l}\text { Analysis based on net power } \\
\text { output and first and second } \\
\text { law efficiencies }\end{array}$ \\
\hline Shokati et al. [125] & 175 & $30^{\ddagger}$ & $1600-4600$ & $\begin{array}{l}\text { Exergoeconomic analysis and } \\
\text { optimization }\end{array}$ \\
\hline $\begin{array}{l}\text { Mergner and } \\
\text { Weimer [126] }\end{array}$ & 120 & 13 & $6-8.5$ & $\begin{array}{l}\text { Analysis with different cycle } \\
\text { configurations }\end{array}$ \\
\hline Arslan [127] & $130^{\dagger}$ & $22^{\ddagger}$ & - & $\begin{array}{l}\text { Optimization and life cycle } \\
\text { cost analysis }\end{array}$ \\
\hline Saffari et al. [128] & 124 & 5 & $1962-2216$ & $\begin{array}{l}\text { Thermodynamic analysis and } \\
\text { optimization with energy and } \\
\text { exergy efficiencies }\end{array}$ \\
\hline Wang et al. [129] & 151.8 & $30^{\ddagger}$ & 263.6 & $\begin{array}{l}\text { Thermodynamic analysis and } \\
\text { optimization with cycle } \\
\text { efficiency }\end{array}$ \\
\hline Fallah et al. [130] & 100 & 25 & 1672 & Advanced exergy analysis \\
\hline Li et al. [131] & $116-128$ & $0-35$ & $1100-2700$ & $\begin{array}{l}\text { Off-design performance } \\
\text { analysis }\end{array}$ \\
\hline Wang and Yu [132] & 120 & - & $500-2000$ & $\begin{array}{l}\text { Working fluid composition } \\
\text { variation following the } \\
\text { ambient conditions }\end{array}$ \\
\hline
\end{tabular}

$\dagger$ Expander inlet temperature.

$\ddagger$ Working fluid condenser outlet temperature.

Campos Rodríguez et al. [120] presented a comparison of a Kalina cycle and an ORC with 15 pure fluids for a geothermal plant in Brazil based on exergy and economic parameters. The optimal Kalina cycle configuration resulted in $17.8 \%$ lower LCOE value than the optimal ORC configuration. A comparison between the Kalina cycle and various ORC 
configurations was also presented by Walraven et al. [121]. Both subcritical and transcritical ORC configurations using about 80 pure working fluids were compared with the Kalina cycle on the basis of cycle exergy efficiency. The results indicated that for geothermal fluid temperatures around $70{ }^{\circ} \mathrm{C}$, the Kalina cycle and the various ORCs perform similarly, but for all other considered heat source temperatures, the ORCs performed better. Li and Dai [122] compared the thermoeconomic performances of a Kalina cycle and a transcritical $\mathrm{CO}_{2}$ power cycle for operation in China. The results indicated that the Kalina cycle performed better than the transcritical $\mathrm{CO}_{2}$ power cycle from both the thermodynamic (net power output and thermal efficiency) and the economic (specific investment cost) aspects.

Coskun et al. [123, 124] presented a comparison of double flash, binary, combined flash/binary, and Kalina cycle power systems for medium temperature geothermal plants in Turkey. The results suggested that the Kalina cycle resulted in the maximum power output and the highest first law and second law efficiencies among the compared cycles. When comparing the capital investment costs for producing a unit amount of electricity, the Kalina and the double flash cycle power systems had similar costs which were the lowest among the compared alternatives. Shokati et al. [125] presented the exergoeconomic analysis and optimization based comparison of a Kalina cycle power system and basic, dual-fluid, and dual-pressure ORC power systems. The various power cycle systems were optimized for maximizing the produced electrical power while simultaneously minimizing the unit cost of the produced power. Among the considered alternatives, the dual-pressure ORC power system resulted in the maximum electrical power produced while the Kalina cycle power system resulted in the minimum cost of the produced power in their respective optimum operating states. From the exergoeconomic perspective, the turbines in the various power cycle systems resulted in the maximum cost rates, therefore these need to be paid more attention to while designing the plants. Mergner and Weimer [126] presented a comparison between the performances of two layouts for a geothermal Kalina cycle power system. The first one is the KCS-34 layout and the second one is a layout based on a Siemens patent (termed as 'KC SG1' in the paper). The main difference between the two layouts is the positioning of the internal heat recovery recuperator. The results indicated that the KC SG1 


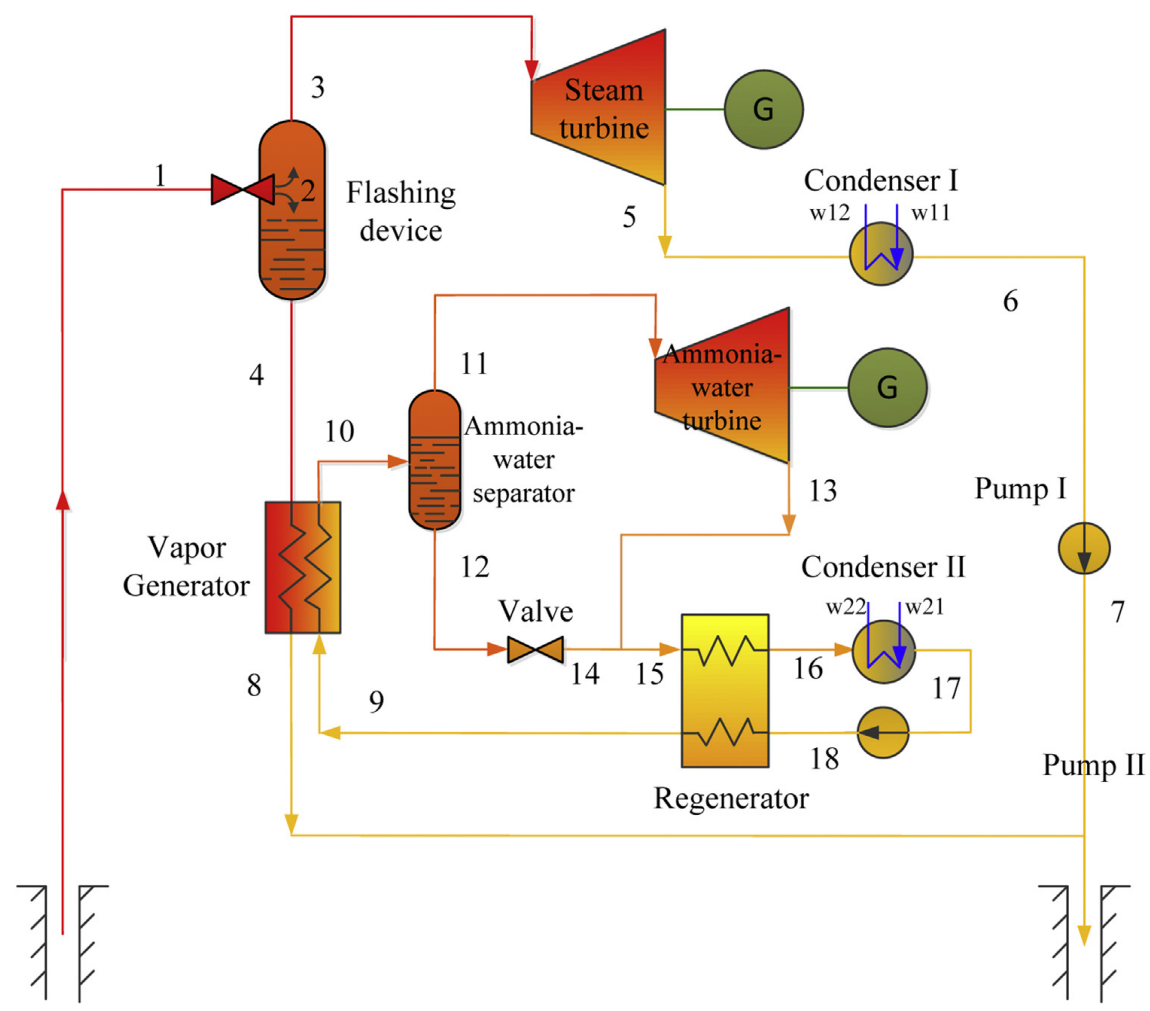

Figure 12: Flash-binary geothermal power plant with a Kalina cycle unit [129].

layout performed slightly better than the KCS-34 layout in terms of cycle efficiency.

Among other studies, Arslan [127] optimized a Kalina cycle power system (KCS-34) for use with medium temperature geothermal sources in Turkey using artificial neural networks. A life cycle cost analysis was also presented. Similarly, Saffari et al. [128] presented the thermodynamic analysis and optimization of a geothermal Kalina cycle power system located in Iceland using an artificial bee colony algorithm. The optimization objectives were to maximize the cycle thermal and exergy efficiencies. A parametric study indicated that the thermal and the exergy efficiencies for the cycle first increased and then decreased with increasing separator inlet temperature and pressure, basic ammonia mass fraction, and the mass flow rate of the working fluid. Wang et al. [129] presented the thermodynamic analysis and optimization of a flash-binary geothermal power plant where the liquid stream from the geothermal flash separator was used as a heat source to the Kalina cycle working fluid. The plant layout is shown in Fig. 12. The results indicated at the presence of an optimal 
flash pressure and optimal ammonia-water turbine inlet pressure and temperature in order to obtain the highest overall plant efficiency. Fallah et al. [130] investigated a geothermal

Kalina cycle power system using advanced exergy analysis. The results suggested to focus on the performance of the condenser, the turbine, and the evaporator from the advanced exergy perspective. The off-design performance analysis of a low temperature geothermal Kalina cycle power system was presented by Li et al. [131]. A sliding pressure strategy was used in order to operate the cycle with varying geothermal source mass flow rate and temperature and the cooling medium inlet temperature. The results indicated that the speed adjustment of the working fluid pump for the sliding pressure operation is more sensitive to the heat source temperature than to the heat sink temperature. However, the heat sink temperature affects the net power output and thermal efficiency of the plant more than the heat source temperature. Wang and $\mathrm{Yu}[132]$ analysed a Kalina cycle layout with the possibility to adjust the working fluid composition to suit the ambient (i.e. cooling medium) conditions.

\subsection{Waste/Exhaust heat recovery Kalina cycle power systems}

The studies analysing Kalina cycle power systems for WHR applications have been conducted for a wide range of heat source temperatures (between around $35{ }^{\circ} \mathrm{C}$ and $440{ }^{\circ} \mathrm{C}$ ) and plant capacities (between around $2 \mathrm{~kW}$ and $25 \mathrm{MW}$ ). Heat recovery possibility from a variety of heat sources has been investigated. The publications include energy, exergy, and exergoeconomic analyses, parametric studies, thermoeconomic analysis and optimizations, and comparison with ORC power systems. Some atypical configurations such as the Kalina split-cycle and dual pressure cycle have also been investigated. Table 8 shows an overview of these studies with their details presented in the following text. In the studies where comparisons were made between the Kalina cycle and other power cycles, Table 8 presents the details corresponding to the Kalina cycle.

Table 8: Studies with Kalina cycle power systems used for WHR applications. $T_{\mathrm{hs}}$ is the heat source temperature and $T_{\mathrm{CS}}$ is the cooling medium temperature. A '-' instead of the value indicates unavailable data.

Reference

$T_{\text {hs }}\left({ }^{\circ} \mathrm{C}\right) \quad T_{\mathrm{cs}}\left({ }^{\circ} \mathrm{C}\right) \quad$ Capacity $(\mathrm{kW}) \quad$ Remarks 


\begin{tabular}{|c|c|c|c|c|}
\hline Matsuda [133] & 120 & 25 & 3300 & $\begin{array}{l}\text { Thermal performance } \\
\text { analysis }\end{array}$ \\
\hline Yue et al. [134] & 439 & 20 & $10-217$ & $\begin{array}{l}\text { Net power output at } \\
\text { various engine loads }\end{array}$ \\
\hline $\begin{array}{l}\text { Rezaee and } \\
\text { Houshmand [135] }\end{array}$ & - & - & 46.9 & $\begin{array}{l}\text { Energy and exergy } \\
\text { analyses }\end{array}$ \\
\hline Gholamian and Zare [136] & 246 & $28^{\ddagger}$ & 11.8 & $\begin{array}{l}\text { Analysis based on net } \\
\text { power output }\end{array}$ \\
\hline Chew et al. [137] & $36-176$ & $30-45$ & 1310 & $\begin{array}{l}\text { Thermodynamic } \\
\text { comparison with ORCs } \\
\text { and heat pumps }\end{array}$ \\
\hline Nemati et al. [138] & 156 & 25 & $600-1000$ & $\begin{array}{l}\text { Analysis based on exergy } \\
\text { efficiency }\end{array}$ \\
\hline $\begin{array}{l}\text { Singh and } \\
\text { Kaushik }[139,140]\end{array}$ & 134.3 & 32.5 & 600 & $\begin{array}{l}\text { Energy and exergy } \\
\text { analyses, exergoeconomic } \\
\text { optimization }\end{array}$ \\
\hline $\begin{array}{l}\text { Singh and } \\
\text { Kaushik }[141,142]\end{array}$ & $119-124$ & $38^{\ddagger}$ & 4300 & Thermoeconomic analysis \\
\hline $\begin{array}{l}\text { Momeni and } \\
\text { Shokouhmand [143] }\end{array}$ & $120-389$ & 27 & $2700-8600$ & $\begin{array}{l}\text { Analysis based on net } \\
\text { power output and first law } \\
\text { efficiency }\end{array}$ \\
\hline Mahmoudi et al. [144] & 136 & 25 & $18500-24900$ & Thermoeconomic analysis \\
\hline Peng et al. $[145,146]$ & $156^{\dagger}$ & $24^{\ddagger}$ & - & $\begin{array}{l}\text { Energy and exergy } \\
\text { analyses }\end{array}$ \\
\hline Zhao et al. [147] & 345.7 & $30^{\ddagger}$ & 25401 & $\begin{array}{l}\text { Analysis based on second } \\
\text { law efficiency }\end{array}$ \\
\hline Li et al. $[148]$ & $105-150$ & $35^{\ddagger}$ & $2-40$ & Thermoeconomic analysis \\
\hline Zare et al. $[149,150]$ & 199.6 & 25 & $27330-38140$ & $\begin{array}{l}\text { Thermodynamic and } \\
\text { exergoeconomic analyses }\end{array}$ \\
\hline Mahmoudi et al. [151] & 214 & 25 & $32300-53250$ & Exergoeconomic analysis \\
\hline
\end{tabular}




\begin{tabular}{|c|c|c|c|c|}
\hline $\begin{array}{l}\text { Larsen et al. [152], Nguyen } \\
\text { et al. [153] }\end{array}$ & 346 & $25-40$ & $1700-1900$ & $\begin{array}{l}\text { Energy, exergy, and cost } \\
\text { analyses for a Kalina } \\
\text { split-cycle }\end{array}$ \\
\hline $\begin{array}{l}\text { Junye et al. [154], Hua } \\
\text { et al. }[155,156]\end{array}$ & $225-350$ & 25 & - & $\begin{array}{l}\text { Thermal performance } \\
\text { analysis and optimization }\end{array}$ \\
\hline $\begin{array}{l}\text { Zhang et al. [157], Chen } \\
\text { et al. [158] }\end{array}$ & $250-340$ & $15-25$ & $470-500$ & $\begin{array}{l}\text { Analysis with power } \\
\text { generation and heating } \\
\text { modes }\end{array}$ \\
\hline Guo et al. [159] & $350-400$ & 25 & $900-1100$ & $\begin{array}{l}\text { Analysis with a } \\
\text { dual-pressure evaporation } \\
\text { cycle configuration }\end{array}$ \\
\hline Zhu et al. [160] & 400 & 25 & - & $\begin{array}{l}\text { Analysis with a } \\
\text { dual-pressure evaporation } \\
\text { cycle configuration }\end{array}$ \\
\hline
\end{tabular}

${ }^{\dagger}$ Expander inlet temperature.

$\ddagger$ Working fluid condenser outlet temperature.

Matsuda [133] presented the thermal performance of a Kalina cycle unit for utilizing low grade heat from a refinery in Japan. Yue et al. [134] presented a comparison of a Kalina cycle and a transcritical ORC with pure fluids for exhaust heat recovery from an internal combustion engine. The net power output from the WHR cycles was calculated for different engine loads (20\% to $100 \%)$. The results suggested that the transcritical ORC is advantageous because of a better overall WHR efficiency, low operation pressure, and simpler cycle configuration. Rezaee and Houshmand [135] presented the energy and exergy analyses of the KCS-11 Kalina cycle power system for WHR from a proton exchange membrane fuel cell. Gholamian and Zare [136] presented a comparison of the Kalina cycle and an ORC for WHR from a solid oxide fuel cell and gas turbine hybrid power plant. The heat input to the WHR power cycles came from the gas turbine exhaust. The results suggested that for this case, the ORC performed better than the Kalina cycle in terms of net power output using the given waste heat stream. Chew et al. [137] presented a comparison 
between using a Kalina cycle, an ORC, and heat pumps in order to improve the energy efficiency of dividing-wall distillation columns through WHR. The results indicated that for a waste heat temperature over $150{ }^{\circ} \mathrm{C}$, the Kalina cycle and the ORC with cooling water as the heat sink are favoured over the heat pump based configurations. Nemati et al. [138] compared the thermodynamic performance of an ORC and a Kalina cycle for WHR from a cogeneration system. The results indicated that from an exergy efficiency perspective, the ORC performs about 0.2 percentage point better with much lower operating pressures (about 10 bar as compared with about 38 bar for the Kalina cycle).

Singh and Kaushik [139, 140] presented the energy analysis, exergy analysis, and exergoeconomic optimization of a Kalina cycle as a bottoming cycle to a coal-fired steam power plant. The KCS-11 layout was analysed in the study. The maximum rate of exergy destruction occurred in the Kalina cycle evaporator and an optimal ammonia mass fraction could be found for each turbine inlet pressure. The turbine had a low exergoeconomic factor, therefore the cycle performance may be improved by investing in a more efficient design. In a similar study, a Brayton-Rankine-Kalina combined triple power cycle using the KCS-34 layout for the Kalina cycle was evaluated from a thermoeconomic perspective [141, 142]. Momeni and Shokouhmand [143] presented a comparison between a Kalina cycle and an ammonia-water Rankine cycle as the bottoming cycle to a gas turbine and steam Rankine combined cycle power plant. The Brayton-Rankine-Kalina cycle power system resulted in lower first law efficiency and net power output than the combination with the ammonia-water Rankine cycle. Mahmoudi et al. [144] presented a thermoeconomic analysis of a combined supercritical $\mathrm{CO}_{2}$ recompression Brayton-Kalina cycle power system. The proposed cycle resulted in up to $10 \%$ higher exergy efficiency and up to $4.9 \%$ lower product unit cost than the configuration without the Kalina cycle. 


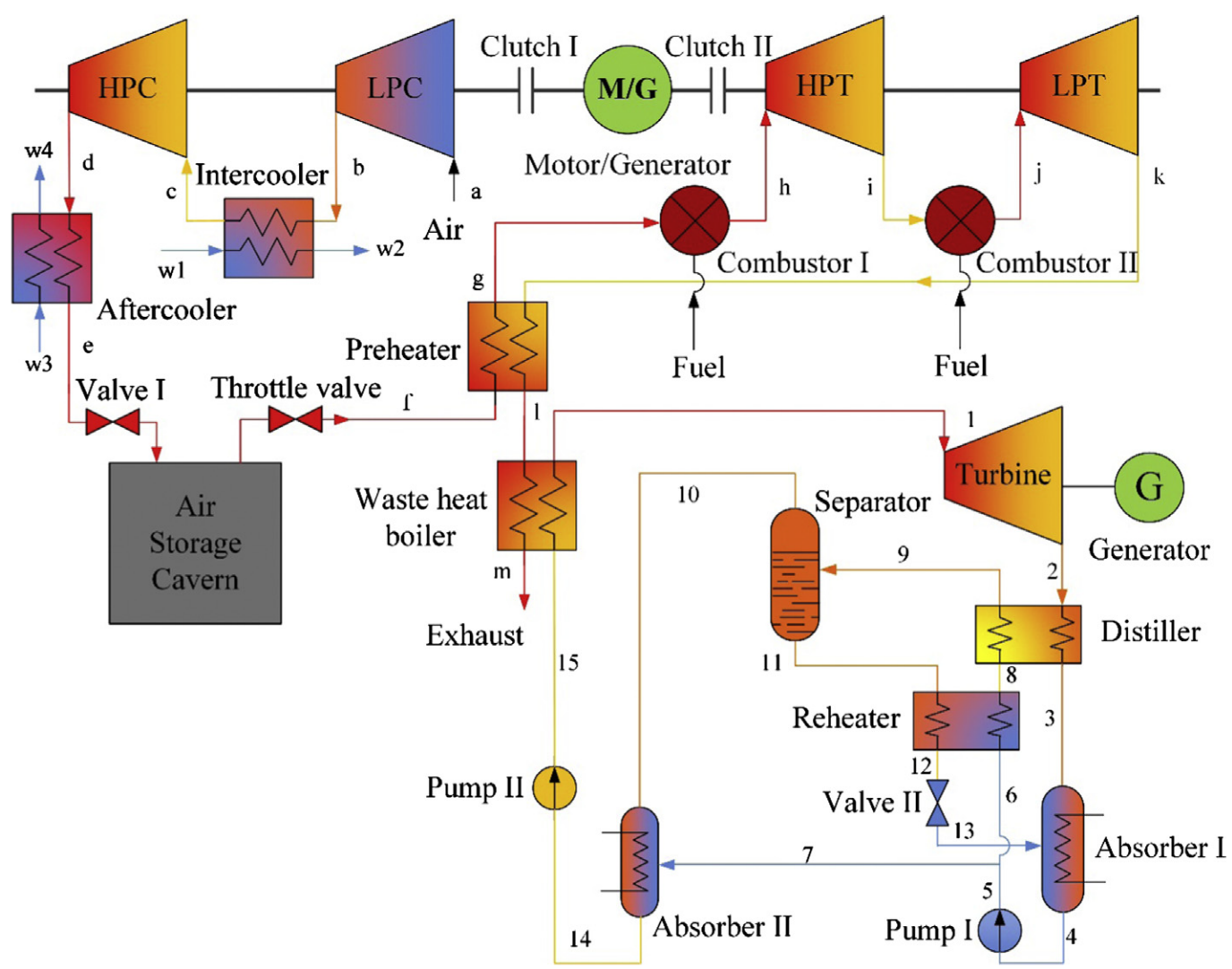

Figure 13: A gas turbine and Kalina cycle integrated power plant with a compressed air energy storage system [147]. 'HPC' is the high pressure compressor, 'LPC' is the low pressure compressor, 'HPT' is the high pressure turbine, and 'LPT' is the low pressure turbine.

Peng et al. $[145,146]$ presented the thermodynamic and exergy analyses of a solar gas turbine coupled with a Kalina bottoming cycle. The heat input to the Kalina cycle came from the compressor intercooling and the gas turbine exhaust air. One of the key advantages from this configuration as compared with a conventional solar tower power plant was that the proposed configuration had the potential to conserve about $69 \%$ of the water consumption in the arid areas where such plants are most likely to be installed and operated. Zhao et al. [147] analysed a gas turbine and Kalina cycle integrated power plant with a compressed air energy storage system. The layout of this configuration is shown in Fig. 13 and includes the KCS-6 Kalina cycle configuration. The results indicated about a 4 percentage point increment in the second law efficiency for the proposed configuration as compared with a configuration 
without the Kalina cycle. Li et al. [148] presented the results from a thermoeconomic comparison between a Kalina cycle unit and an ORC unit operating with a compressed air energy storage system. The thermoeconomically optimal Kalina cycle unit resulted in a higher exergy efficiency than the corresponding ORC unit by about 6 percentage points. Zare et al. [149, 150] presented a thermodynamic comparison between a Kalina cycle unit and an ORC unit for WHR from a gas turbine modular helium reactor plant. They also presented the results from the exergoeconomic assessment of employing the Kalina cycle unit for this purpose. The results indicated that the configuration with the ORC unit had higher first and second law efficiencies than the configuration with the Kalina cycle unit. The ORC unit also required a lower operating pressure than the Kalina cycle unit. The results from the exergoeconomic analysis of a similar configuration were presented by Mahmoudi et al. [151].

The Kalina cycle power system has also been investigated in variations other than its standard layouts. Larsen et al. [152] presented the optimization and a simplified cost analysis of the Kalina split-cycle power system with primary focus on the boiler, the turbine, and the mixing system subsections of the cycle. They also compared the performance of a normal Kalina cycle power sytem to that of the Kalina split-cycle power system. Nguyen et al. [153] conducted an exergy analysis of the Kalina split-cycle power system. These studies $[152,153]$ concluded that the Kalina split-cycle power system with reheat was better than the normal Kalina cycle power system in terms of cycle efficiency but this improvement came at the price of increased capital investment cost and a more complex cycle design. Junye et al. [154] analysed the thermal performance of a modified Kalina cycle power system. The modification in the layout was the addition of a recuperative preheater and a water-cooled solution cooler in the cycle. The results indicated a higher power recovery through better recuperation within the cycle. In a continuation to this study, the cycle with the preheater, but without the solution cooler, was further optimized and analysed $[155,156]$. The objectives were to maximize the power generation from the available waste heat and analyse the variable turbine inlet composition power regulation approach. Zhang et al. [157, 158] analysed a similar Kalina cycle layout but for possible operation either in power generation mode 
for non-heating season or in heating mode for heating season (as ammonia-water Rankine cycle). Guo et al. [159] also presented an analysis of a similar layout and compared its performance with that of a dual-pressure evaporation Kalina cycle power system. A similar comparative study was made by Zhu et al. [160] with a dual-pressure Kalina cycle layout with the second evaporator operating in parallel with the economizer.

\subsection{Other studies}

Table 9 shows an overview of some generic studies evaluating a Kalina cycle power system together with a study on a biomass-fired Kalina cycle power system. In the studies where comparisons were made between the Kalina cycle and other power cycles, Table 9 presents the details corresponding to the Kalina cycle. The generic studies have been conducted for a wide range of heat source temperatures (between around $60{ }^{\circ} \mathrm{C}$ and $400{ }^{\circ} \mathrm{C}$ ) and plant capacities (between around $2 \mathrm{~kW}$ and 1.3 MW), while the biomass-fired Kalina cycle was evaluated for heat source temperatures between $300{ }^{\circ} \mathrm{C}$ and $525{ }^{\circ} \mathrm{C}$ and plant capacities between $450 \mathrm{~kW}$ and $610 \mathrm{~kW}$. The details of these studies are presented in the following text.

Table 9: Other studies with power cycles using ammonia-water mixture as the working fluid. $T_{\mathrm{hs}}$ is the heat source temperature and $T_{\mathrm{cs}}$ is the cooling medium temperature. A '-' instead of the value indicates unavailable data.

\begin{tabular}{lllll}
\hline Reference & $T_{\mathrm{hs}}\left({ }^{\circ} \mathrm{C}\right)$ & $T_{\mathrm{cs}}\left({ }^{\circ} \mathrm{C}\right)$ & Capacity $(\mathrm{kW})$ & Remarks \\
\hline Yari et al. [161] & 120 & $40^{\ddagger}$ & $600-1300$ & $\begin{array}{l}\text { Exergoeconomic analysis } \\
\text { Victor et al. [162] }\end{array}$ \\
$100-250^{\dagger}$ & $25-40^{\ddagger}$ & - & $\begin{array}{l}\text { Working fluid composition } \\
\text { optimization }\end{array}$ \\
& & & & Feasibility study with \\
Elsayed et al. [163] & $60-200$ & 10 & - & alternative zeotropic \\
& & & & mixtures in Kalina cycle \\
& & & & Second law analysis \\
Eller et al. [164] & $200-400$ & 15 & & Analysis based on net power \\
Li et al. [165] & $105-150$ & $35^{\dagger}$ & $8-26$ & output and cycle efficiency
\end{tabular}


He et al. [166]

Sadeghi et al. [167] 150-200 ${ }^{\dagger}$ -

Cao et al. [168]
127

5-30

$300-525^{\dagger} \quad 20^{\ddagger}$
$2-5$

$220-478$

450-610
Analysis based on net power

output

Analysis based on cycle efficiency

Analysis based on net power

output and cycle efficiency

${ }^{\dagger}$ Expander inlet temperature.

$\ddagger$ Working fluid condenser outlet temperature.

Yari et al. [161] presented an exergoeconomic comparison between a Kalina cycle, a trilateral Rankine cycle, and an ORC with pure working fluids for low grade heat sources. The analysed Kalina cycle layout was KCS-11. The results indicated that using an ORC unit for power generation from low grade heat sources is the most advantageous among the compared alternatives from an economic perspective. Victor et al. [162] optimized the composition of the working fluids in a Kalina cycle unit and an ORC unit with mixtures as working fluid. For the comparison, binary combinations of several fluids were considered including hydrocarbons, hydrofluorocarbons, and alcohols. Alcohol-water mixtures were also considered. The results indicated that different working fluid compositions are optimal for different operating temperatures and pressures for the Kalina cycle unit, and the alcohol-water mixtures could increase the cycle efficiency for heat source temperatures between $220{ }^{\circ} \mathrm{C}$ to $250{ }^{\circ} \mathrm{C}$. Elsayed et al. [163] evaluated the feasibility of using alternative zeotropic mixtures in the Kalina cycle KCS-11 power system. Among the 19 evaluated binary mixtures, the R1270/R290 mixture outperformed the ammonia-water mixture in terms of the cycle thermal efficiency, while the other mixtures exhibited similar performances as the ammonia-water mixture. In a similar kind of study, Eller et al. [164] analysed the use of several binary mixtures in a Kalina cycle with heat source temperatures between $200{ }^{\circ} \mathrm{C}$ and $400{ }^{\circ} \mathrm{C}$. The performance results were compared with those of subcritical and supercritical ORCs. The results indicated that the ORC power system performed better than the Kalina cycle power system by up to $13 \%$ in terms of the second law efficiency. 


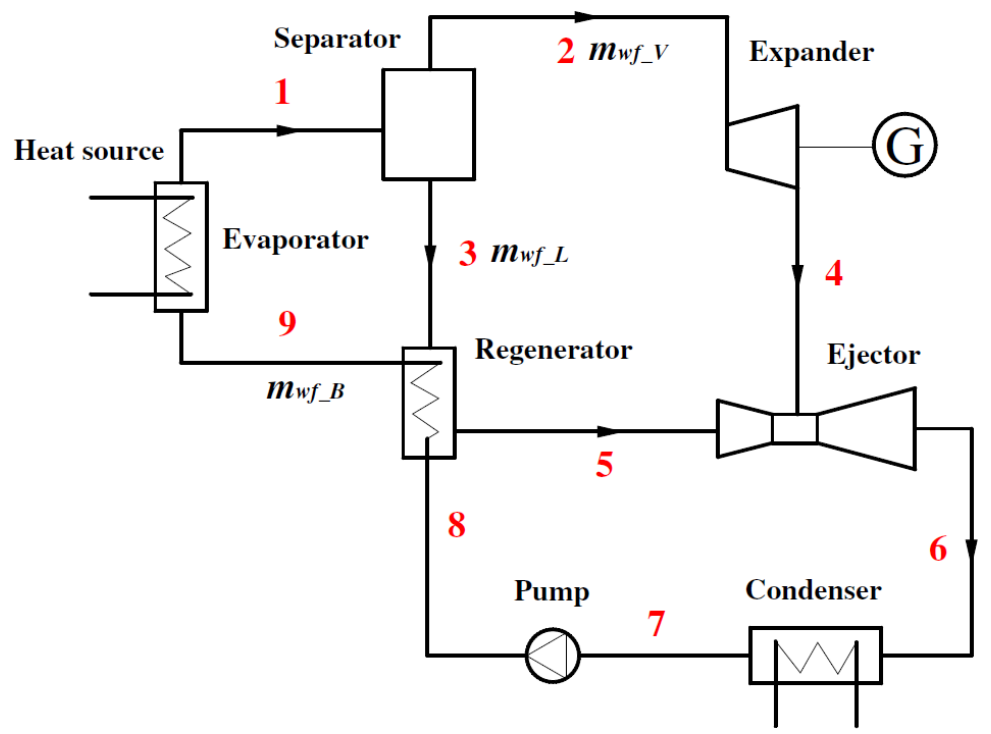

Figure 14: A Kalina cycle power system with ejector [165]. In the layout, the subscripts 'wf_B', 'wf_V', and 'wf_L' represent the basic working fluid, the ammonia-rich vapour, and the ammonia-lean liquid, respectively.

Li et al. [165] analysed a Kalina cycle power system with ejector as shown in Fig. 14. In the proposed configuration, the ejector replaced the combination of a throttle valve and a mixer typically used in a Kalina cycle unit. This was done so as to avoid the throttling losses in the cycle while reducing the pressure at the turbine outlet for better cycle efficiency. The results indicated that both the net power output and the cycle thermal efficiency are higher for the Kalina cycle power system with ejector than the Kalina cycle power system without one. He et al. [166] proposed two Kalina cycle (KCS-11) configurations by replacing the throttle valve with a two-phase expander in order to increase the utilization of low grade heat sources. One of the modified configurations resulted in $2 \%$ to $9.4 \%$ higher net work output than the standard Kalina cycle power system with a throttle valve. In a similar kind of study, Sadeghi et al. [167] proposed and optimized a double-turbine Kalina cycle power system with two separators using the artificial bee colony algorithm. Optimal values for the inlet temperature and pressure for one of the separators were reported for obtaining the highest thermal efficiency. Cao et al. [168] presented a thermodynamic analysis of a biomass-fired Kalina cycle power system in which the cycle working fluid is preheated in a regenerative heater just before entering the boiler using an extracted stream from the turbine. 
The results suggested that an optimal combination of the turbine extraction pressure and cycle efficiency.

\section{Discussion}

Most of the research on the use of zeotropic mixtures until now has focused primarily on the thermodynamic performance analysis of the power cycles. The power output from any power cycle is mainly governed by how much heat is extracted from the heat source and the thermal efficiency of the power cycle. Thus, for example, when optimizing an ORC power system, the maximum cycle pressure which maximizes the power output from the cycle is typically not the same as the one maximizing the thermal efficiency. Additionally, there may be a dependency on the minimum allowable exit temperature for the heat source. In this regard, the results have mostly indicated at better thermodynamic performances with mixtures than with pure fluids from the energy and exergy efficiency perspectives, especially for low temperature heat sources. In particular, the highest performance improvements as compared with using pure fluids have been observed when the temperature glide of the mixture matches the temperature profile of the cooling medium in the condenser. A possible explanation is that this is the most effective way of maximizing the average temperature difference between the average temperature of heat supply and the average temperature of heat rejection, in turn maximizing the thermal efficiency of the power cycle.

In addition, a possible explanation for the largest improvement in terms of thermal efficiency for low temperature heat sources is that the relative increase in temperature difference between the average temperature of heat supply and the average temperature of heat rejection (due to the use of mixtures) is comparatively higher for low temperature heat sources than for high temperature heat sources where a significant portion of the heat supply might be used for superheating and/or preheating. For mixture power cycles in general, the optimal mixture compositions have been found to be dependent on the cycle layout (i.e. the presence and/or location of the recuperators) for both the ORC power systems and the ammonia-water power systems, the objective function (thermodynamic, economic, or ther- 
moeconomic), the assumed pinch point conditions, and the relation between the heat source temperature and the working fluid evaporation pressure and critical temperature.

In many studies, the performance of mixture power cycles has been compared with

that of the power cycles with the pure fluids that constitute the mixture. In such cases, it cannot always be concluded with certainty that the analysed mixtures are also more efficient than other pure working fluids that could have been considered for similar applications and operating conditions. Therefore, a recent trend has been to consider the various fluids (both pure fluids and mixtures) as an optimization decision variable. In this way, all the possible pure fluids and their suitable mixtures will be considered within the optimization resulting in the optimal solution with the best pure fluid or mixture. One bottleneck in this approach is the significantly increased computational time because of the huge number of combinations of fluids and the various compositions for each such combination. Another recent approach has been to include a computer aided molecular design process within the numerical procedure in order to design (rather than identify from the input alternatives) the optimal chemical composition of the working fluid for the best satisfaction of the objective function.

\subsection{ORC power systems}

Table 10 presents the recommended mixtures from the studies on ORC power systems where various mixtures were compared for different applications. The table presents the overview from only those studies where a particular mixture was specifically identified as optimal among the compared alternatives. As may be observed from Table 10, the literature consists of analyses based on several parameters such as net power output from the plant, the first and second law efficiencies, the volumetric expander work, the turbine size parameter, or a combination of multiple performance indicators. From the literature on mixture ORCs, it may be observed that hundreds of fluids have been considered in many combinations in various studies depending on the application and the operating conditions. The applications are primarily about utilizing renewable or waste heat energy sources. Most of the studies analysed the use of binary mixtures, but few studies also considered the use of mixtures 
with three or more components. 
Table 10: Recommended mixtures for various applications and operating conditions for ORC power systems. $T_{\mathrm{hs}}$ is the heat source temperature. A '-' instead of the value indicates unavailable data.

\begin{tabular}{|c|c|c|c|c|}
\hline Reference & Application & $T_{\mathrm{hs}}\left({ }^{\circ} \mathrm{C}\right)$ & Performance indicator & Recommended mixture(s) \\
\hline Prasad et al. [12] & Solar & 100 & $\begin{array}{l}\text { Second law efficiency, volumetric } \\
\text { expander work }\end{array}$ & $\mathrm{R} 290 / \mathrm{R} 600 / \mathrm{R} 600 \mathrm{a}$ \\
\hline $\begin{array}{l}\text { Baldasso } \\
\text { et al. }[13]\end{array}$ & Solar & 150 & $\begin{array}{l}\text { First law efficiency, annual } \\
\text { electricity production }\end{array}$ & Cyclopentane/cyclohexane \\
\hline Mavrou et al. [18] & Solar & $80-95$ & $\begin{array}{l}\text { First law efficiency, exergy } \\
\text { efficiency }\end{array}$ & Neopentane/1,1,1-trifluoropentane \\
\hline Mavrou et al. [19] & Solar & $80-95$ & $\begin{array}{l}\text { Net power output, first law } \\
\text { efficiency }\end{array}$ & Neopentane/2-fluoromethoxy-2-methylpropane \\
\hline Mavrou et al. [20] & Solar & $80-95$ & $\begin{array}{l}\text { Net power output, first law } \\
\text { efficiency }\end{array}$ & 1,1,1-trifluoropropane/1-fluoromethoxypropane \\
\hline Heberle et al. [22] & Geothermal & $80-180$ & Second law efficiency & $\begin{array}{l}\mathrm{R} 227 \mathrm{ea} / \mathrm{R} 245 \mathrm{fa}\left(T_{\mathrm{hs}}<180{ }^{\circ} \mathrm{C}\right), \mathrm{R} 600 \mathrm{a} / \mathrm{R} 601 \mathrm{a} \\
\left(T_{\mathrm{hs}}=180{ }^{\circ} \mathrm{C}\right)\end{array}$ \\
\hline $\begin{array}{l}\text { Heberle and } \\
\text { Brüggemann [23] }\end{array}$ & Geothermal & $100-180$ & $\begin{array}{l}\text { Specific investment cost, } \\
\text { electricity generation cost }\end{array}$ & $\begin{array}{l}\text { R227ea/R245fa, R290/R600a, R600a/R601a } \\
\text { (depending on } T_{\mathrm{hs}} \text { ) }\end{array}$ \\
\hline Kang et al. [30] & Geothermal & 110 & Net power output & $\mathrm{R} 245 \mathrm{fa} / \mathrm{R} 600 \mathrm{a}$ \\
\hline Sadeghi et al. [32] & Geothermal & 100 & $\begin{array}{l}\text { Net power output, turbine size } \\
\text { parameter }\end{array}$ & $\mathrm{R} 407 \mathrm{a}$ \\
\hline
\end{tabular}




\begin{tabular}{|c|c|c|c|c|}
\hline $\begin{array}{l}\text { Habka and } \\
\text { Ajib [33] }\end{array}$ & Geothermal & $80-120$ & $\begin{array}{l}\text { Net power output, first law } \\
\text { efficiency, second law efficiency, } \\
\text { turbine size parameter }\end{array}$ & $\mathrm{R} 22 \mathrm{~m}, \mathrm{R} 422 \mathrm{a}, \mathrm{R} 438 \mathrm{a}$ \\
\hline Baik et al. [35] & Geothermal & 100 & Net power output & $\mathrm{R} 125 / \mathrm{R} 245 \mathrm{fa}$ \\
\hline $\begin{array}{l}\text { Radulovic and } \\
\text { Castaneda }[36]\end{array}$ & Geothermal & $87-207$ & $\begin{array}{l}\text { First law efficiency, second law } \\
\text { efficiency }\end{array}$ & R124/R143a \\
\hline Xiao et al. [42] & WHR & 150 & Multi-objective function & $\mathrm{R} 245 \mathrm{fa} / \mathrm{R} 601\left(T_{\mathrm{ev}}<117^{\circ} \mathrm{C}\right.$ and $\left.T_{\mathrm{cd}}<47^{\circ} \mathrm{C}\right)$ \\
\hline Kolahi et al. [45] & WHR & 425.7 & $\begin{array}{l}\text { Net power output, first law } \\
\text { efficiency, second law efficiency }\end{array}$ & R236ea/cyclohexane \\
\hline Yang et al. [56] & WHR & $170-545$ & $\begin{array}{l}\text { Net power output, first law } \\
\text { efficiency, second law efficiency, }\end{array}$ & $\mathrm{R} 402 \mathrm{~b}, \mathrm{R} 407 \mathrm{~b}, \mathrm{R} 415 \mathrm{~b}$ \\
\hline & & & $\begin{array}{l}\text { WHR efficiency, power output } \\
\text { increasing rate }\end{array}$ & \\
\hline Zhou et al. [58] & WHR & - & $\begin{array}{l}\text { Net power output, first law } \\
\text { efficiency }\end{array}$ & RC318/R1234yf \\
\hline Shu et al. [59] & WHR & 519 & First law efficiency, exergy loss & R11/benzene \\
\hline Song and $\mathrm{Gu}[60]$ & WHR & 300 & $\begin{array}{l}\text { Net power output, second law } \\
\text { efficiency }\end{array}$ & R141b/cyclohexane \\
\hline $\begin{array}{l}\text { Braimakis } \\
\text { et al. [61] }\end{array}$ & WHR & $150-300$ & Second law efficiency & $\begin{array}{l}\text { R290/R600, R600/hexane, R600/cyclopentane } \\
\text { (depending on } T_{\mathrm{hs}} \text { ) }\end{array}$ \\
\hline Lee et al. [62] & WHR & 87.7 & $\begin{array}{l}\text { Net power output, first law } \\
\text { efficiency }\end{array}$ & $\mathrm{R} 14 / \mathrm{R} 23 / \mathrm{R} 601$ \\
\hline
\end{tabular}




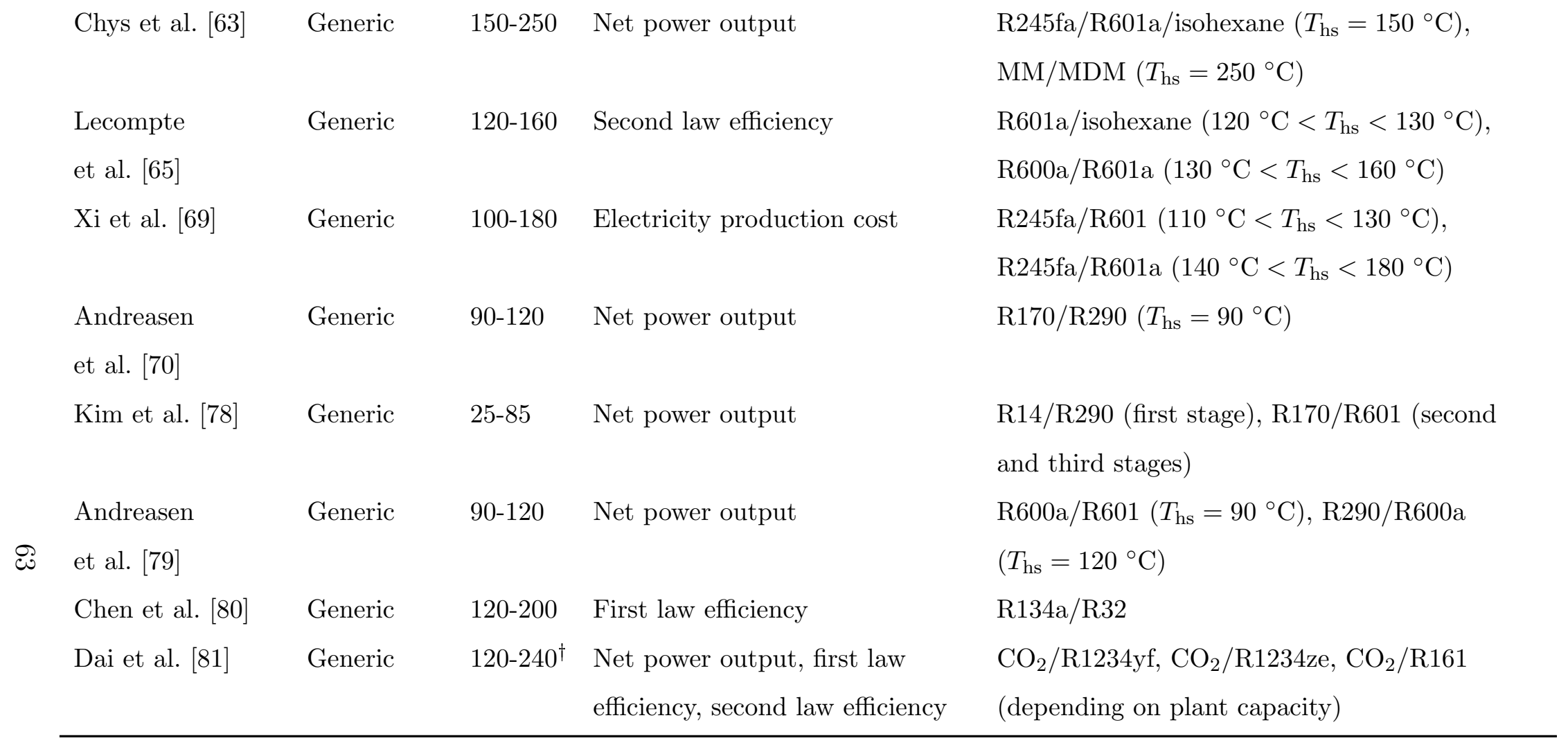

${ }^{\dagger}$ Expander inlet temperature. 


\subsection{Ammonia-water power systems}

The ammonia-water mixture based power cycles have been investigated in a significant number of publications, both independently and in comparison with other power cycles. This is because of the possibility to use ammonia-water mixture for a very wide range are present, e.g. Heberle and Brüggemann [23] mentioned that the use of fluid mixtures in ORC power systems resulted in a higher specific investment cost as compared with using pure fluids for most of the considered cases, whereas Li and Dai [44] presented an opposite 
trend.

These contradictions are present because of one or more of the following reasons: (1) different types and temperatures of the heat source, (2) different ways to estimate the thermophysical properties of the fluids and the heat transfer coefficients in the single and the two-phase regions, (3) consideration of different and limited number of fluids in the various studies, (4) different capacity of the considered cases (few $\mathrm{kW}$ to MW), and (5) different cost estimation methods and the associated assumptions. The heat sources have a significant impact on the estimation of the heat exchanger areas for the boiler or the heat recovery vapour generator. If flue gases are considered as the heat source, then it is most likely that the overall heat transfer coefficient will be nearly equal to the heat transfer coefficient on the gas side of the boiler and the estimation of the heat transfer coefficient on the working fluid side becomes less relevant. Whereas if liquids such as hot water or thermal oil are considered as the heat sources, then the heat transfer coefficients on the working fluid side have a significant impact on the overall heat transfer coefficients and therefore only applicable correlations should be used in such cases, particularly for the two-phase region. Similarly, for the condensation process, suitable corrections such as the Silver-Bell-Ghaly method [169] should be used.

There are only a small number of studies which present a thermoeconomic analysis by estimating the cost of electricity generation or LCOE with the size estimation of the various power plant components (e.g. Refs. [23, 46, 47, 69] for small capacity ORC power systems and Refs. [109, 114, 120] for Kalina cycle power systems). Even in these studies, it is not always that detailed suitable heat transfer models are used or the part-load performance of the power plants is considered. For heat sources which are consistently available throughout the year such as geothermal hot water or an industrial waste heat stream, not considering the part-load performance does not affect the estimations significantly. But for sources such as solar energy, the variations in the available incident energy over the year must be taken into account in the LCOE estimations. Among the publications with the estimation of LCOE, there are again some contradictory results such as both pure fluids and mixtures resulting in lower LCOE depending on the heat source characteristics and the associated 
modelling assumptions. Furthermore, more recent publications have favoured mixtures in low temperature ORC power systems with regards to $\operatorname{LCOE}[23,69]$, whereas for the high temperature systems, the Kalina cycle power system was found to result in worse performance than state-of-the-art steam Rankine cycle power system [114]. In conclusion, it is difficult to definitively conclude anything generic on the economic performance of the power systems with fluid mixtures and further research is required especially for low grade heat recovery ORC and ammonia-water power systems and the comparison of their LCOE with state-of-the-art solutions.

\section{Research prospects}

Since so many fluid mixture combinations have been considered for a wide range of operating conditions, it is difficult to recommend any particular optimal fluids for mixture ORC power systems. It is therefore recommended that the optimal fluids and their compositions should be identified on a case by case basis through a thorough thermoeconomic analysis. As a first stage in this process, the fluids to be considered must be shortlisted based on their global warming and ozone depletion potentials and on the local legislation which might recommend phasing out of certain groups of fluids in the next 5-10 years. These include, for example, the phasing out of hydrofluorocarbons as per the Montreal protocol and limitations on the use of fluorinated gases as per a European Parliament directive [170-172].

The future research should then focus on combining the thermodynamic design models with the part-load performance and economic models for forming a more conclusive outlook on the true thermoeconomic benefits of using mixtures for power generation applications. This requires developing robust methods for estimating the size/geometry of the various cycle components along with developing realistic cost functions for various operating conditions and plant capacities in order to assess the associated costs. One important aspect from the system level design perspective is the assumption regarding the location of the pinch points in the heat exchanger, especially during two-phase flow. In this regard, recent studies have clearly highlighted that the location of the occurrence of pinch point should not be assumed beforehand as it completely depends on the curvature of the two-phase temperature 
profile of the zeotropic mixture. Therefore, it is recommended that this aspect is directly incorporated in the thermodynamic design simulation through heat exchanger discretization in order to avoid designs with unusually low pinch point temperature differences or second law violations.

More research is also needed in identifying the underlying causes for the dependence of the cycle efficiency and net power output on the thermophysical properties of the fluid mixtures, e.g. how critical temperature and pressure, specific heat capacity, or similar properties of the working fluids affect the overall cycle performance for given operating conditions and optimization criteria, how these parameters affect the performance depending on the minimum allowable heat source exit temperature, and so on. As most of the research on the use of zeotropic mixtures comes from the analysis of refrigeration cycles and heat pumps, not much data is available on the heat transfer coefficients for these mixtures in the temperature ranges suitable for power cycles. This is one of areas where significant potential for future research is present from both experimental and numerical perspectives. Heat exchanger designs specifically suitable for mixture two-phase heat transfer need to be developed. Similarly, suitable designs for expanders for use with mixtures also need to be developed, analysed, and optimized for various operating conditions and scales.

\section{Conclusion}

The use of zeotropic fluid mixtures in energy conversion systems has been widely studied for refrigeration plants and heat pumps in the last few decades. However it is only recently that the use of these mixtures in power cycles has attracted increased interest because of the possibility to reduce the irreversibility during a two-phase heat transfer process, thereby resulting in better thermodynamic performance. Based on the review of the recent literature, the following overall conclusions may be drawn. Most of the studies considered the use of mixtures for the conversion of low grade heat to power. In general, the results indicate better thermodynamic performance when using the mixtures with low heat source temperatures than with high heat source temperatures. The majority of the studies primarily focused on the thermodynamic performance of the power cycles with zeotropic mixtures and 
assessing the potential to improve the thermodynamic performance as compared with using pure working fluids. The use of mixtures have mostly been found to result in improved thermodynamic performance of the power cycle with respect to the net power output and first and second law efficiencies.

Only a few studies also investigated the economic aspects of mixture power cycles, primarily through the estimation of the capital investment costs and sometimes through the estimation of LCOE or payback periods. The general consensus from the economic studies until now is that the mixture power cycles incur higher capital investment costs than pure fluid power cycles, mainly because of bigger heat exchanger area requirements. Recent studies however also indicate lower values of LCOE with mixture power cycles than the pure fluid power cycles, particularly for low temperature ORC power systems. This is because of compensating the higher capital investment costs by the higher revenue generation with mixture power cycles due to better cycle efficiencies and higher net power outputs.

The future research on the use of zeotropic mixtures may focus on more thorough thermoeconomic analyses including the thermodynamic design, the part-load performance, and the economic models in the numerical models. More research is also required towards developing more robust heat transfer and pressure drop correlations together with more reliable cost functions for better estimation of the thermoeconomic performance of the mixture power cycles. Lastly, research is also required on developing novel heat exchanger and expander designs suitable specifically for use with zeotropic mixtures.

\section{Nomenclature}

CNG compressed natural gas

$\mathrm{CO}_{2} \quad$ carbon dioxide

LCOE levelized cost of electricity

LNG liquefied natural gas

$\mathrm{MD}_{2} \mathrm{M}$ decamethyltetrasiloxane

MDM octamethyltrisiloxane 
MM hexamethyldisiloxane

ORC organic Rankine cycle

OTEC ocean thermal energy conversion

$\mathrm{SF}_{6} \quad$ sulphur hexafluoride

$T_{\text {cd }} \quad$ condensation temperature, ${ }^{\circ} \mathrm{C}$

$T_{\mathrm{cs}} \quad$ cooling medium temperature, ${ }^{\circ} \mathrm{C}$

$T_{\mathrm{ev}} \quad$ evaporation temperature, ${ }^{\circ} \mathrm{C}$

$T_{\mathrm{hs}} \quad$ heat source temperature, ${ }^{\circ} \mathrm{C}$

WHR waste/exhaust heat recovery

\section{Acknowledgement}

The authors thank Martin Ryhl Kærn, Jesper Graa Andreasen, and Jonas Kjær Jensen, Department of Mechanical Engineering, Technical University of Denmark for the valuable discussions and inputs.

\section{References}

[1] R. Radermacher, Y. Hwang, Vapor compression heat pumps with refrigerant mixtures, Taylor \& Francis Group, LLC, Florida, USA, 1st edn., 2005.

[2] B. M. Fronk, S. Garimella, In-tube condensation of zeotropic fluid mixtures: A review, International Journal of Refrigeration 36 (2) (2013) 534-561.

[3] M. R. Kærn, A. Modi, J. K. Jensen, F. Haglind, An assessment of transport property estimation methods for ammonia-water mixtures and their influence on heat exchanger size, International Journal of Thermophysics 36 (7) (2015) 1468-1497.

[4] M. R. Kærn, A. Modi, J. K. Jensen, J. G. Andreasen, F. Haglind, An assessment of in-tube flow boiling correlations for ammonia-water mixtures and their influence on heat exchanger size, Applied Thermal Engineering 93 (2016) 623-638.

[5] H. Chen, D. Y. Goswami, E. K. Stefanakos, A review of thermodynamic cycles and working fluids for the conversion of low-grade heat, Renewable and Sustainable Energy Reviews 14 (9) (2010) 3059-3067. 
[6] B. F. Tchanche, G. Lambrinos, A. Frangoudakis, G. Papadakis, Low-grade heat conversion into power using organic Rankine cycles A review of various applications, Renewable and Sustainable Energy Reviews 15 (8) (2011) 3963-3979.

[7] P. Colonna, E. Casati, C. Trapp, T. Mathijssen, J. Larjola, T. Turunen-Saaresti, A. Uusitalo, Organic Rankine cycle power systems: From the concept to current technology, applications, and an outlook to the future, Journal of Engineering for Gas Turbines and Power 137 (2015) 100801.

[8] H. Zhai, Q. An, L. Shi, V. Lemort, S. Quoilin, Categorization and analysis of heat sources for organic Rankine cycle systems, Renewable and Sustainable Energy Reviews 64 (2016) 790-805.

[9] P. Linke, A. Papadopoulos, P. Seferlis, Systematic methods for working fluid selection and the design, integration and control of organic Rankine cycles - A Review, Energies 8 (6) (2015) 4755-4801.

[10] C. N. Markides, Low-concentration solar-power systems based on organic Rankine cycles for distributed-scale applications: Overview and further developments, Frontiers in Energy Research 3 (2015) 1-16.

[11] J. Bao, L. Zhao, A review of working fluid and expander selections for organic Rankine cycle, Renewable and Sustainable Energy Reviews 24 (2013) 325-342.

[12] G. S. C. Prasad, C. S. Kumar, S. S. Murthy, G. Venkatarathnam, Performance of an organic Rankine cycle with multicomponent mixtures, Energy 88 (2015) 1-7.

[13] E. Baldasso, J. G. Andreasen, A. Modi, F. Haglind, A. Stoppato, Performance analysis of a solar driven organic Rankine cycle using multi-component working fluids, in: ECOS 2015 - The 28th International Conference on Efficiency, Cost, Optimization, Simulation and Environmental Impact of Energy Systems, Pau, France, 2015.

[14] J. J. Bao, L. Zhao, W. Z. Zhang, A novel auto-cascade low-temperature solar Rankine cycle system for power generation, Solar Energy 85 (11) (2011) 2710-2719.

[15] X. D. Wang, L. Zhao, Analysis of zeotropic mixtures used in low-temperature solar Rankine cycles for power generation, Solar Energy 83 (5) (2009) 605-613.

[16] P. Garg, P. Kumar, K. Srinivasan, P. Dutta, Evaluation of carbon dioxide blends with isopentane and propane as working fluids for organic Rankine cycles, Applied Thermal Engineering 52 (2) (2013) 439-448.

[17] P. Garg, P. Kumar, K. Srinivasan, P. Dutta, Evaluation of isopentane, R-245fa and their mixtures as working fluids for organic Rankine cycles, Applied Thermal Engineering 51 (1-2) (2013) 292-300.

[18] P. Mavrou, A. I. Papadopoulos, M. Stijepovic, P. Seferlis, P. Linke, S. Voutetakis, Assessment of working fluid mixtures for solar organic Rankine cycles, Chemical Engineering Transactions 39 (2014) 283-288.

[19] P. Mavrou, A. I. Papadopoulos, P. Seferlis, P. Linke, S. Voutetakis, Selection of working fluid mix- 
tures for flexible Organic Rankine Cycles under operating variability through a systematic nonlinear sensitivity analysis approach, Applied Thermal Engineering 89 (2015) 1054-1067.

[20] P. Mavrou, A. I. Papadopoulos, M. Z. Stijepovic, P. Seferlis, P. Linke, S. Voutetakis, Novel and conventional working fluid mixtures for solar Rankine cycles: Performance assessment and multi-

[33] M. Habka, S. Ajib, Evaluation of mixtures performances in Organic Rankine Cycle when utilizing the geothermal water with and without cogeneration, Applied Energy 154 (2015) 567-576.

[34] J. Lu, J. Zhang, S. Chen, Y. Pu, Analysis of organic Rankine cycles using zeotropic mixtures as 
working fluids under different restrictive conditions, Energy Conversion and Management 126 (2016) 704-716.

[35] Y.-J. Baik, M. Kim, K.-C. Chang, Y.-S. Lee, H.-K. Yoon, Power enhancement potential of a mixture transcritical cycle for a low-temperature geothermal power generation, Energy 47 (1) (2012) 70-76.

[36] J. Radulovic, N. I. B. Castaneda, On the potential of zeotropic mixtures in supercritical ORC powered by geothermal energy source, Energy Conversion and Management 88 (2014) 365-371.

[37] M. Preißinger, F. Heberle, D. Brüggemann, Advanced organic rankine cycle for geothermal application, International Journal of Low-Carbon Technologies 8 (2013) i62-i68.

[38] J. Hærvig, K. Sørensen, T. J. Condra, Guidelines for optimal selection of working fluid for an organic Rankine cycle in relation to waste heat recovery, Energy 96 (2016) 592-602.

[39] O. A. Oyewunmi, A. I. Taleb, A. J. Haslam, C. N. Markides, On the use of SAFT-VR Mie for assessing large-glide fluorocarbon working-fluid mixtures in organic Rankine cycles, Applied Energy 163 (2016) 263-282.

[40] Y.-R. Li, M.-T. Du, C.-M. Wu, S.-Y. Wu, C. Liu, Potential of organic Rankine cycle using zeotropic mixtures as working fluids for waste heat recovery, Energy 77 (2014) 509-519.

[41] M. E. Mondejar, M. Thern, Analysis of isentropic mixtures for their use as working fluids in organic Rankine cycles, Environmental Progress \& Sustainable Energy (In Press).

[42] L. Xiao, S. Y. Wu, T. T. Yi, C. Liu, Y. R. Li, Multi-objective optimization of evaporation and condensation temperatures for subcritical organic Rankine cycle, Energy 83 (2015) 723-733.

[43] S.-Y. Wu, S.-M. Zhou, L. Xiao, The determination and matching analysis of pinch point temperature difference in evaporator and condenser of organic Rankine cycle for mixed working fluid, International Journal of Green Energy 13 (5) (2016) 470-480.

[44] S. Li, Y. Dai, Thermo-economic analysis of waste heat recovery ORC using zeotropic mixtures, ASCE Journal of Energy Engineering 141 (4) (2014) 04014050.

[45] M. Kolahi, M. Yari, S. M. S. Mahmoudi, F. Mohammadkhani, Thermodynamic and economic performance improvement of ORCs through using zeotropic mixtures: Case of waste heat recovery in an offshore platform, Case Studies in Thermal Engineering 8 (2016) 51-70.

[46] V. L. Le, A. Kheiri, M. Feidt, S. Pelloux-Prayer, Thermodynamic and economic optimizations of a waste heat to power plant driven by a subcritical ORC (Organic Rankine Cycle) using pure or zeotropic working fluid, Energy 78 (2014) 622-638.

[47] Y. Feng, T. Hung, Y. Zhang, B. Li, J. Yang, Y. Shi, Performance comparison of low-grade ORCs (organic Rankine cycles) using R245fa, pentane and their mixtures based on the thermoeconomic multi-objective optimization and decision makings, Energy 93 (2015) 2018-2029.

[48] Y. Feng, T. Hung, K. Greg, Y. Zhang, B. Li, J. Yang, Thermoeconomic comparison between pure and 
mixture working fluids of organic Rankine cycles (ORCs) for low temperature waste heat recovery, Energy Conversion and Management 106 (2015) 859-872.

[49] T. Weith, F. Heberle, M. Preißinger, D. Brüggemann, Performance of siloxane mixtures in a hightemperature organic Rankine cycle considering the heat transfer characteristics during evaporation, Energies 7 (9) (2014) 5548-5565.

[50] F. Heberle, D. Brüggemann, Thermo-economic analysis of zeotropic mixtures and pure working fluids in Organic Rankine Cycles for waste heat recovery, Energies 9 (2016) 226.

[51] C. Guo, X. Du, L. Yang, Y. Yang, Organic Rankine cycle for power recovery of exhaust flue gas, Applied Thermal Engineering 75 (2015) 135-144.

[52] S. Song, H. Zhang, Z. Lou, F. Yang, K. Yang, H. Wang, C. Bei, Y. Chang, B. Yao, Performance analysis of exhaust waste heat recovery system for stationary CNG engine based on organic Rankine cycle, Applied Thermal Engineering 76 (2015) 301-309.

[53] H. Wang, H. Zhang, F. Yang, S. Song, Y. Chang, C. Bei, K. Yang, Parametric optimization of regenerative organic Rankine cycle system for diesel engine based on particle swarm optimization, Energies 8 (9) (2015) 9751-9776.

[54] J. Zhang, H. Zhang, K. Yang, F. Yang, Z. Wang, G. Zhao, H. Liu, E. Wang, B. Yao, Performance analysis of regenerative organic Rankine cycle (RORC) using the pure working fluid and the zeotropic mixture over the whole operating range of a diesel engine, Energy Conversion and Management 84 (2014) 282-294.

[55] H.-C. Jung, L. Taylor, S. Krumdieck, An experimental and modelling study of a $1 \mathrm{~kW}$ organic Rankine cycle unit with mixture working fluid, Energy 81 (2015) 601-614.

[56] K. Yang, H. Zhang, Z. Wang, J. Zhang, F. Yang, E. Wang, B. Yao, Study of zeotropic mixtures of ORC (organic Rankine cycle) under engine various operating conditions, Energy 58 (2013) 494-510.

[57] K. Yang, H. Zhang, E. Wang, S. Song, C. Bei, Y. Chang, H. Wang, B. Yao, Study on mixed working fluids with different compositions in organic Rankine cycle (ORC) systems for vehicle diesel engines, Entropy 16 (2014) 4769-4787.

[58] Y. Zhou, Y. Wu, F. Li, L. Yu, Performance analysis of zeotropic mixtures for the dual-loop system combined with internal combustion engine, Energy Conversion and Management 118 (2016) 406-414.

[59] G. Shu, Y. Gao, H. Tian, H. Wei, X. Liang, Study of mixtures based on hydrocarbons used in ORC (Organic Rankine Cycle) for engine waste heat recovery, Energy 74 (C) (2014) 428-438.

[60] J. Song, C. W. Gu, Analysis of ORC (Organic Rankine Cycle) systems with pure hydrocarbons and mixtures of hydrocarbon and retardant for engine waste heat recovery, Applied Thermal Engineering 89 (2015) 693-702.

[61] K. Braimakis, M. Preißinger, D. Brüggemann, S. Karellas, K. Panopoulos, Low grade waste heat 
recovery with subcritical and supercritical Organic Rankine Cycle based on natural refrigerants and their binary mixtures, Energy 88 (2015) 80-92.

[62] U. Lee, K. Kim, C. Han, Design and optimization of multi-component organic rankine cycle using liquefied natural gas cryogenic exergy, Energy 77 (2014) 520-532.

[63] M. Chys, M. van den Broek, B. Vanslambrouck, M. De Paepe, Potential of zeotropic mixtures as working fluids in organic Rankine cycles, Energy 44 (1) (2012) 623-632.

[64] S. Aghahosseini, I. Dincer, Comparative performance analysis of low-temperature Organic Rankine Cycle (ORC) using pure and zeotropic working fluids, Applied Thermal Engineering 54 (1) (2013) $35-42$.

[65] S. Lecompte, B. Ameel, D. Ziviani, M. van den Broek, M. De Paepe, Exergy analysis of zeotropic mixtures as working fluids in Organic Rankine Cycles, Energy Conversion and Management 85 (2014) $727-739$.

[66] L. Zhao, J. Bao, Thermodynamic analysis of organic Rankine cycle using zeotropic mixtures, Applied Energy 130 (2014) 748-756.

[67] D. Luo, A. Mahmoud, F. Cogswell, Evaluation of Low-GWP fluids for power generation with Organic Rankine Cycle, Energy 85 (2015) 481-488.

[68] Y. Wu, Y. Zhu, L. Yu, Thermal and economic performance analysis of zeotropic mixtures for Organic Rankine Cycles, Applied Thermal Engineering 96 (2016) 57-63.

[69] H. Xi, M.-J. Li, Y.-L. He, Y. Zhang, Economical evaluation and optimization of organic Rankine cycle with mixture working fluids using R245fa as flame retardant, Applied Thermal Engineering 113 (2017) 1056-1070.

[70] J. G. Andreasen, U. Larsen, T. Knudsen, L. Pierobon, F. Haglind, Selection and optimization of pure and mixed working fluids for low grade heat utilization using organic Rankine cycles, Energy 73 (2014) 204-213.

[71] J. G. Andreasen, M. R. Kærn, L. Pierobon, U. Larsen, F. Haglind, Multi-objective optimization of organic Rankine cycle power plants using pure and mixed working fluids, Energies 9 (322) (2016) 1-15.

[72] T. Deethayat, T. Kiatsiriroat, C. Thawonngamyingsakul, Performance analysis of an organic Rankine cycle with internal heat exchanger having zeotropic working fluid, Case Studies in Thermal Engineering 6 (2015) 155-161.

[73] T. Deethayat, A. Asanakham, T. Kiatsiriroat, Performance analysis of low temperature organic Rankine cycle with zeotropic refrigerant by Figure of Merit (FOM), Energy 96 (2016) 96-102.

[74] B. Dong, G. Xu, Y. Cai, H. Li, Analysis of zeotropic mixtures used in high-temperature Organic Rankine cycle, Energy Conversion and Management 84 (2014) 253-260.

[75] C. Guo, X. Du, D. Y. Goswami, L. Yang, Investigation on working fluids selection for organic rankine 
cycles with low-temperature heat sources, International Journal of Green Energy 13 (6) (2016) 556565.

[76] P. Collings, Z. Yu, E. Wang, A dynamic organic Rankine cycle using a zeotropic mixture as the working fluid with composition tuning to match changing ambient conditions, Applied Energy 171 (2016) 581-591.

[77] J. I. Yoon, C. H. Son, S. H. Seol, H. U. Kim, S. J. Ha, S. H. Jung, H. J. Kim, H. S. Lee, Performance analysis of OTEC power cycle with a liquid-vapor ejector using R32/R152a, Heat and Mass Transfer 51 (11) (2015) 1597-1605.

[78] K. Kim, U. Lee, C. Kim, C. Han, Design and optimization of cascade organic Rankine cycle for recovering cryogenic energy from liquefied natural gas using binary working fluid, Energy 88 (2015) 304-313.

[79] J. G. Andreasen, U. Larsen, T. Knudsen, F. Haglind, Design and optimization of a novel organic Rankine cycle with improved boiling process, Energy 91 (2015) 48-59.

[80] H. Chen, D. Y. Goswami, M. M. Rahman, E. K. Stefanakos, A supercritical Rankine cycle using zeotropic mixture working fluids for the conversion of low-grade heat into power, Energy 36 (1) (2011) 549-555.

[81] B. Dai, M. Li, Y. Ma, Thermodynamic analysis of carbon dioxide blends with low GWP (global warming potential) working fluids-based transcritical Rankine cycles for low-grade heat energy recovery, Energy 64 (2014) 942-952.

[82] L. Pan, X. Wei, W. Shi, Performance analysis of a zeotropic mixture (R290/CO2) for trans-critical power cycle, Chinese Journal of Chemical Engineering 23 (3) (2015) 572-577.

[83] T. Rajabloo, P. Iora, C. Invernizzi, Mixture of working fluids in ORC plants with pool boiler evaporator, Applied Thermal Engineering 98 (2016) 1-9.

[84] Q. Liu, Y. Duan, Z. Yang, Effect of condensation temperature glide on the performance of organic Rankine cycles with zeotropic mixture working fluids, Applied Energy 115 (2014) 394-404.

[85] Y. Zhou, F. Zhang, L. Yu, Performance analysis of the partial evaporating organic Rankine cycle (PEORC) using zeotropic mixtures, Energy Conversion and Management 129 (2016) 89-99.

[86] G. B. Abadi, E. Yun, K. C. Kim, Experimental study of a 1 kw organic Rankine cycle with a zeotropic mixture of R245fa/R134a, Energy 93 (2015) 2363-2373.

[87] Y. Wang, X. Liu, X. Ding, Y. Weng, Experimental investigation on the performance of ORC power system using zeotropic mixture R601a/R600a, International Journal of Energy Research (In Press).

[88] D. P. Molina-Thierry, A. Flores-Tlacuahuac, Simultaneous optimal design of organic mixtures and rankine cycles for low-temperature energy recovery, Industrial and Engineering Chemistry Research 54 (13) (2015) 3367-3383. 
[89] J. Bao, L. Zhao, Experimental research on the influence of system parameters on the composition shift for zeotropic mixture (isobutane/pentane) in a system occurring phase change, Energy Conversion and Management 113 (2016) 1-15.

[90] A. I. Papadopoulos, M. Stijepovic, P. Linke, P. Seferlis, S. Voutetakis, Toward optimum working fluid mixtures for organic Rankine cycles using molecular design and sensitivity analysis, Industrial \& Engineering Chemistry Research 52 (2013) 12116-12133.

[91] X. Zhang, M. He, Y. Zhang, A review of research on the Kalina cycle, Renewable and Sustainable Energy Reviews 16 (7) (2012) 5309-5318.

[92] F. Mohammadkhani, F. Ranjbar, M. Yari, A comparative study on the ammonia-water based bottoming power cycles: The exergoeconomic viewpoint, Energy 87 (2015) 425-434.

[93] C. Koroneos, D. Rovas, Exergy analysis of geothermal electricity using the Kalina cycle, International Journal of Exergy 12 (1) (2013) 54-69.

[94] K. H. Kim, C. H. Han, K. Kim, Effects of ammonia concentration on the thermodynamic performances of ammonia-water based power cycles, Thermochimica Acta 530 (2012) 7-16.

[95] K. H. Kim, C. H. Han, K. Kim, Comparative exergy analysis of ammonia-water based Rankine cycles with and without regeneration Chul Ho Han, International Journal of Exergy 12 (3) (2013) 344-361.

[96] K. H. Kim, K. C. Kim, Thermodynamic performance analysis of a combined power cycle using low grade heat source and LNG cold energy, Applied Thermal Engineering 70 (2014) 50-60.

[97] K. C. Kim, J. M. Ha, K. H. Kim, Exergy analysis of a combined power cycle using low-grade heat source and LNG cold energy, International Journal of Exergy 17 (3) (2015) 374-400.

[98] J. Wang, Z. Yan, M. Wang, Y. Dai, Thermodynamic analysis and optimization of an ammonia-water power system with LNG (liquefied natural gas) as its heat sink, Energy 50 (2013) 513-522.

[99] L. Pierobon, M. Rokni, Thermodynamic analysis of an integrated gasification solid oxide fuel cell plant with a Kalina cycle, International Journal of Green Energy 12 (2015) 610-619.

[100] G. Khankari, S. Karmakar, Power generation from coal mill rejection using Kalina cycle, Journal of Energy Resources Technology 138 (2016) 052004.

[101] M. Wang, A. Manera, S. Qiu, G. H. Su, Ammonia-water mixture property code (AWProC) development, verification and Kalina cycle design for nuclear power plant, Progress in Nuclear Energy 91 (2016) 26-37.

[102] S. Mohtaram, W. Chen, T. Zargar, J. Lin, Energy-exergy analysis of compressor pressure ratio effects on thermodynamic performance of ammonia water combined cycle, Energy Conversion and Management 134 (2017) 77-87.

[103] A. Momeni, P. Ahmadi, H. S. Hamut, M. Ashjaee, Thermo-economic assessment of three-stage combined cycle power system using ammonia-water mixture, Mechanics \& Industry 17 (5) (2016) 502. 
[115] A. Modi, F. Haglind, Thermodynamic optimisation and analysis of four Kalina cycle layouts for high temperature applications, Applied Thermal Engineering 76 (2015) 196-205.

[116] A. Modi, J. G. Andreasen, M. R. Kærn, F. Haglind, Part-load performance of a high temperature

[117] J. Wang, Z. Yan, E. Zhou, Y. Dai, Parametric analysis and optimization of a Kalina cycle driven by solar energy, Applied Thermal Engineering 50 (1) (2013) 408-415.

[118] F. R. Astaraei, M. Sameti, M. A. Jokar, F. Pourfayaz, Numerical simulation of solar-driven Kalina 
cycle performance for centralized residential buildings in Iran, Intelligent Buildings International (In

[119] A. Modi, Numerical evaluation of the Kalina cycle for concentrating solar power plants, Phd thesis, Technical University of Denmark, Kongens Lngyby, Denmark, 2015.

[120] C. E. Campos Rodríguez, J. C. Escobar Palacio, O. J. Venturini, E. E. Silva Lora, V. M. Cobas, D. Marques dos Santos, F. R. Lofrano Dotto, V. Gialluca, Exergetic and economic comparison of ORC and Kalina cycle for low temperature enhanced geothermal system in Brazil, Applied Thermal Engineering 52 (2013) 109-119.

[121] D. Walraven, B. Laenen, W. D'Haeseleer, Comparison of thermodynamic cycles for power production from low-temperature geothermal heat sources, Energy Conversion and Management 66 (2013) 220233.

[122] S. Li, Y. Dai, Thermo-economic comparison of Kalina and $\mathrm{CO} 2$ transcritical power cycle for low temperature geothermal sources in China, Applied Thermal Engineering 70 (2014) 139-152.

[123] A. Coskun, A. Bolatturk, M. Kanoglu, Thermodynamic and economic analysis and optimization of power cycles for a medium temperature geothermal resource, Energy Conversion and Management 78 (2014) 39-49.

[124] A. Coskun, A. Bolatturk, M. Kanoglu, Thermodynamic and economic analysis and optimization of various power cycles for a geothermal resource, Energy Sources, Part A: Recovery, Utilization, and Environmental Effects 38 (6) (2016) 850-856.

[125] N. Shokati, F. Ranjbar, M. Yari, Exergoeconomic analysis and optimization of basic, dual-pressure and dual-fluid ORCs and Kalina geothermal power plants: A comparative study, Renewable Energy 83 (2015) 527-542.

[126] H. Mergner, T. Weimer, Performance of ammonia-water based cycles for power generation from low enthalpy heat sources, Energy 88 (2015) 93-100.

[127] O. Arslan, Power generation from medium temperature geothermal resources: ANN-based optimization of Kalina cycle system-34, Energy 36 (5) (2011) 2528-2534.

[128] H. Saffari, S. Sadeghi, M. Khoshzat, P. Mehregan, Thermodynamic analysis and optimization of a geothermal Kalina cycle system using Artificial Bee Colony algorithm, Renewable Energy 89 (2016) $154-167$.

[129] J. Wang, J. Wang, Y. Dai, P. Zhao, Thermodynamic analysis and optimization of a flash-binary geothermal power generation system, Geothermics 55 (2015) 69-77.

[130] M. Fallah, S. M. S. Mahmoudi, M. Yari, R. A. Ghiasi, Advanced exergy analysis of the Kalina cycle applied for low temperature enhanced geothermal system, Energy Conversion and Management 108 (2016) 190-201. 
[131] H. Li, D. Hu, M. Wang, Y. Dai, Off-design performance analysis of Kalina cycle for low temperature geothermal source, Applied Thermal Engineering 107 (2016) 728-737.

[132] E. Wang, Z. Yu, A numerical analysis of a composition-adjustable Kalina cycle power plant for power generation from low-temperature geothermal sources, Applied Energy 180 (2016) 834-848.

[133] K. Matsuda, Low heat power generation system, Applied Thermal Engineering 70 (2) (2014) 10561061.

[134] C. Yue, D. Han, W. Pu, W. He, Comparative analysis of a bottoming transcritical ORC and a Kalina cycle for engine exhaust heat recovery, Energy Conversion and Management 89 (2015) 764-774.

[135] V. Rezaee, A. Houshmand, Energy and exergy analysis of a combined power generation system using PEM fuel cell and Kalina Cycle System 11, Periodica Polytechnica Chemical Engineering 60 (2) (2015) 98-105.

[136] E. Gholamian, V. Zare, A comparative thermodynamic investigation with environmental analysis of SOFC waste heat to power conversion employing Kalina and Organic Rankine Cycles, Energy Conversion and Management 117 (2016) 150-161.

[137] J. M. Chew, C. C. S. Reddy, G. P. Rangaiah, Improving energy efficiency of dividing-wall columns using heat pumps, Organic Rankine Cycle and Kalina Cycle, Chemical Engineering and Processing: Process Intensification 76 (2014) 45-59.

[138] A. Nemati, H. Nami, F. Ranjbar, M. Yari, A comparative thermodynamic analysis of ORC and Kalina cycles for waste heat recovery: A case study for CGAM cogeneration system, Case Studies in Thermal Engineering 9 (2017) 1-13.

[139] O. Singh, S. Kaushik, Energy and exergy analysis and optimization of Kalina cycle coupled with a coal fired steam power plant, Applied Thermal Engineering 51 (1-2) (2013) 787-800.

[140] O. K. Singh, S. C. Kaushik, Exergoeconomic analysis of a Kalina cycle coupled coal-fired steam power plant, Internationa Journal of Exergy 14 (1) (2014) 38-59.

[141] O. Singh, S. Kaushik, Thermoeconomic evaluation and optimization of a Brayton-Rankine-Kalina combined triple power cycle, Energy Conversion and Management 71 (2013) 32-42.

[142] O. K. Singh, S. C. Kaushik, Reducing CO2 emission and improving exergy based performance of natural gas fired combined cycle power plants by coupling Kalina cycle, Energy 55 (2013) 1002-1013.

[143] A. Momeni, H. Shokouhmand, Thermodynamic modelling of three-stage combined cycle power systems utilising ammonia-water mixture as a working fluid in bottoming cycle, International Journal of Exergy 14 (3) (2014) 320.

[144] S. M. S. Mahmoudi, A. D. Akbari, M. A. Rosen, Thermoeconomic analysis and optimization of a new combined supercritical carbon dioxide recompression Brayton/Kalina cycle, Sustainability 8 (10) (2016) 1079. 
[145] S. Peng, H. Hong, H. Jin, Z. Wang, An integrated solar thermal power system using intercooled gas turbine and Kalina cycle, Energy 44 (2012) 732-740.

[146] S. Peng, H. Hong, Exergy analysis of solar gas turbine system coupled with Kalina cycle, International Journal of Exergy 18 (2) (2015) 192-213.

[147] P. Zhao, J. Wang, Y. Dai, Thermodynamic analysis of an integrated energy system based on compressed air energy storage (CAES) system and Kalina cycle, Energy Conversion and Management 98 (2015) 161-172.

[148] R. Li, H. Wang, E. Yao, S. Zhang, Thermo-economic comparison and parametric optimizations among two compressed air energy storage system based on Kalina cycle and ORC, Energies 10 (15) (2017) $1-19$.

[149] V. Zare, S. Mahmoudi, M. Yari, On the exergoeconomic assessment of employing Kalina cycle for GT-MHR waste heat utilization, Energy Conversion and Management 90 (2015) 364-374.

[150] V. Zare, S. M. S. Mahmoudi, A thermodynamic comparison between organic Rankine and Kalina cycles for waste heat recovery from the Gas Turbine-Modular Helium Reactor, Energy 79 (C) (2015) $398-406$.

[151] S. M. S. Mahmoudi, A. Pourreza, A. D. Akbari, M. Yari, Exergoeconomic evaluation and optimization of a novel combined augmented Kalina cycle/gas turbine-modular helium reactor, Applied Thermal Engineering 109 (2016) 109-120.

[152] U. Larsen, T.-V. Nguyen, T. Knudsen, F. Haglind, System analysis and optimisation of a Kalina split-cycle for waste heat recovery on large marine diesel engines, Energy 64 (2014) 484-494.

[153] T.-V. Nguyen, T. Knudsen, U. Larsen, F. Haglind, Thermodynamic evaluation of the Kalina split-cycle concepts for waste heat recovery applications, Energy 71 (2014) 277-288.

[154] H. Junye, C. Yaping, W. Jiafeng, Thermal performance of a modified ammonia-water power cycle for reclaiming mid/low-grade waste heat, Energy Conversion and Management 85 (2014) 453-459.

[155] J. Hua, Y. Chen, J. Wu, Z. Zhi, C. Dong, Waste heat supply-side power regulation with variable concentration for turbine in Kalina cycle, Applied Thermal Engineering 91 (2015) 583-590.

[156] J. Hua, G. Li, Y. Chen, X. Zhao, Q. Li, Optimization of thermal parameters of boiler in triple-pressure Kalina cycle for waste heat recovery, Applied Thermal Engineering 91 (2015) 1026-1031.

[157] Z. Zhang, Z. Guo, Y. Chen, J. Wu, J. Hua, Power generation and heating performances of integrated system of ammonia-water Kalina-Rankine cycle, Energy Conversion and Management 92 (2015) 517522.

[158] Y. Chen, Z. Guo, J. Wu, Z. Zhang, J. Hua, Energy and exergy analysis of integrated system of ammonia-water Kalina-Rankine cycle, Energy 90 (2015) 2028-2037.

[159] Z. Guo, Z. Zhang, Y. Chen, J. Wu, C. Dong, Dual-pressure vaporization Kalina cycle for cascade 
reclaiming heat resource for power generation, Energy Conversion and Management 106 (2015) 557565.

[160] Z. Zhu, Z. Zhang, Y. Chen, J. Wu, Parameter optimization of dual-pressure vaporization Kalina cycle with second evaporator parallel to economizer, Energy 112 (2016) 420-429.

[161] M. Yari, A. S. Mehr, V. Zare, S. M. S. Mahmoudi, M. A. Rosen, Exergoeconomic comparison of TLC (trilateral Rankine cycle), ORC (organic Rankine cycle) and Kalina cycle using a low grade heat source, Energy 83 (2015) 712-722.

[162] R. A. Victor, J. K. Kim, R. Smith, Composition optimisation of working fluids for Organic Rankine Cycles and Kalina cycles, Energy 55 (2013) 114-126.

[163] A. Elsayed, M. Embaye, R. Al-Dadah, S. Mahmoud, A. Rezk, Thermodynamic performance of kalina cycle system 11 (KCS11): Feasibility of using alternative zeotropic mixtures, International Journal of Low-Carbon Technologies 8 (SUPPL1) (2013) 69-78.

[164] T. Eller, F. Heberle, D. Brüggemann, Second law analysis of novel working fluid pairs for waste heat recovery by the Kalina cycle, Energy 119 (2017) 188-198.

[165] X. Li, Q. Zhang, X. Li, A Kalina cycle with ejector, Energy 54 (2013) 212-219.

[166] J. He, C. Liu, X. Xu, Y. Li, S. Wu, J. Xu, Performance research on modified KCS (Kalina cycle system) 11 without throttle valve, Energy 64 (2014) 389-397.

[167] S. Sadeghi, H. Saffari, N. Bahadormanesh, Optimization of a modified double-turbine Kalina cycle by using Artificial Bee Colony algorithm, Applied Thermal Engineering 91 (2015) 19-32.

[168] L. Cao, J. Wang, Y. Dai, Thermodynamic analysis of a biomass-fired Kalina cycle with regenerative heater, Energy 77 (2014) 760-770.

[169] K. J. Bell, M. A. Ghaly, An approximate generalized design method for multicomponent/partial condensers, in: 13th National Heat Transfer Conference, AIChE-ASME, Denver, Colorado, USA, 1972.

[170] Ozone Secretariat, Handbook for the Montreal Protocol on substances that deplete the ozone layer, Tech. Rep., UNEP, 2006.

[171] Regulation (EU) no 517/2014 of the European Parliament and of the Council on Fluorinated Greenhouse Gases and repealing regulation (EC) no 842/2006, Official Journal of the European Union .

[172] M. E. Mondejar, S. Cignitti, J. Abildskov, J. M. Woodley, F. Haglind, Prediction of properties of new halogenated olefins using two group contribution approaches, Fluid Phase Equilibria 433 (2016) $79-96$. 